\title{
Dietary lipids with potential to affect satiety: mechanisms and evidence
}

Article

Accepted Version

Maher, T. and Clegg, M. E. (2019) Dietary lipids with potential to affect satiety: mechanisms and evidence. Critical Reviews in Food Science and Nutrition, 59 (10). pp. 1619-1644. ISSN 1040-8398 doi:

https://doi.org/10.1080/10408398.2017.1423277 Available at https://centaur.reading.ac.uk/80375/

It is advisable to refer to the publisher's version if you intend to cite from the work. See Guidance on citing.

To link to this article DOI: http://dx.doi.org/10.1080/10408398.2017.1423277

Publisher: Taylor and Francis

All outputs in CentAUR are protected by Intellectual Property Rights law, including copyright law. Copyright and IPR is retained by the creators or other copyright holders. Terms and conditions for use of this material are defined in the End User Agreement.

\section{www.reading.ac.uk/centaur}

\section{CentAUR}

Central Archive at the University of Reading 
Reading's research outputs online 
1 Dietary lipids with potential to affect satiety: Mechanisms and evidence.

3 Tyler Maher ${ }^{1}$ and Miriam E Clegg ${ }^{*}$

4

$5{ }^{1}$ Oxford Brookes Centre for Nutrition and Health, Department of Sport, Health Sciences and Social

6 Work, Faculty of Health and Life Sciences, Oxford Brookes University, Gipsy Lane, Oxford OX3

$7 \quad$ 0BP, UK; email: tmaher@brookes.ac.uk, mclegg@brookes.ac.uk

8

$9 \quad *$ Corresponding author: Miriam Clegg, Functional Food Centre, Department of Sport and Health

10 Sciences, Faculty of Health and Life Sciences, Oxford Brookes University, Gipsy Lane, Oxford

11 OX3 0BP, UK

12 Email: mclegg@ brookes.ac.uk; Ph: +44 1865484365

13

14

15 Running title: Functional lipids and satiety

16

17 Keywords: Medium-Chain Triglycerides; conjugated linoleic acid, Short-Chain Fatty Acids, 18 Diacylglycerol, $n$-3 PUFA, Small Particle Lipids.

19

20

21

22

23

24

25

26

27

28

29

30

31 
33 Dietary fat has been implicated in the rise of obesity due to its energy density, palatability and weak

34 effects on satiety. As fat is a major contributor to overall energy intake, incorporating fat with 35 satiating properties could potentially reduce energy intake. This review outlines the potential 36 mechanisms, as far as we know, by which Medium-Chain Triglycerides (MCT), Conjugated 37 Linoleic Acid (CLA), Short-Chain Fatty Acids (SCFA), Diacylglycerol (DAG), n-3 PUFA, and 38 Small Particle Lipids, exerts their satiating effects. The evidence suggests that the lipid with the 39 most potential to enhance satiety is MCT. SCFA can also promote satiety, but oral administration 40 has been linked to poor tolerability rather than satiety. Data on the appetite effects of CLA is limited 41 but does suggest potential. Research comparing these lipids to each other is also lacking and should 42 be explored to elucidate which of these 'functional lipids' is the most beneficial in enhancing 43 satiety.

\section{4}

45

46

47

48

49

50

51

52

53

54

55

56 
Introduction

58 The continual growth of global obesity is well documented (WHO 2000), as is the concomitant rise

59 of comorbidities such as type 2 diabetes, various cancers and cardiovascular disease (Guh et al.

60 2009). The main driver of weight gain is a positive energy balance, where an individual consumes

61 more energy than they expend, for a prolonged period. The current obesogenic environment we live

62 in can promote obesity due to the large volume of time spent sedentary (Deforche et al. 2015; Dong,

63 Block, and Mandel 2004) as well as increases in the energy density (Stelmach-Mardas et al. 2016),

64 portion size (Ello-Martin, Ledikwe, and Rolls 2005) and relative cost (Drewnowski and Darmon

65 2005) of food, all promoting overconsumption. Dietary fat has also been implicated in the rise of

66 obesity due to its energy density, palatability and weak effects on satiety (Blundell et al. 1993;

67 Blundell and MacDiarmid 1997).

68 Appetite is the internal driving force for the search, choice and ingestion of food (De Graaf et al.

69 2004). Humans eat in episodes consisting of either meals or snacks (Gibney and Wolever 1997).

70 The way in which food intake is controlled is described within the satiety cascade (Blundell,

71 Rogers, and Hill 1987). Satiation occurs during the course of eating and eventually brings the

72 period of eating to an end. Satiety occurs after the end of an eating episode and is the situation in

73 which initiation of further eating is inhibited (Blundell et al. 2010). Calorie restriction is a common

74 method employed by individuals trying to achieve weight loss (Das et al. 2007). The lack of success

75 of many of these calorie-restricted diets lies in the individual's failure to adhere to the diet

76 (Heymsfield et al. 2007), due to feelings of intense hunger, constant thoughts of food, and

77 emotional changes; all of which can culminate in temptations to break the diet (Franklin et al.

78 1948). Foods or ingredients with the potential to enhance satiety could be beneficial in augmenting

79 the success of calorie restricted diets, by decreasing the adverse effects associated with low energy

80 intake and prolonging the feeling of fullness (Chambers, McCrickerd, and Yeomans 2015). Indeed, 
81 results have shown that consumers are willing to try satiety-promoting foods and that many would also prefer a greater amount of foods with this functional element (Hetherington et al. 2013).

83 Although dietary fat can lead to passive overconsumption (Green et al. 2000), there is a growing

84 body of research which suggests that some fats may elicit stronger satiety responses than others.

85 These fats may not be able to match the satiating properties of protein or carbohydrate on an 86 isocaloric basis (Blundell and MacDiarmid 1997); however given that fat should make up to 35\% of 87 energy intake (Department of Health 1984) and some obese individuals have reported intakes exceeding 40\% (Dreon et al. 1988), incorporating lipids with satiating properties has the potential to reduce overall energy intake. Data investigating lipids with satiating properties is still inconclusive.

The purpose of this review is to highlight fat with the potential to promote satiety in humans, the mechanisms by which they work and to evaluate which has the greatest potential to be utilised in weight management strategies. We discuss the potential role and mechanisms of medium chain triglycerides, conjugated linoleic acid, short-chain fatty acids, diacylglycerol, omega-3 polyunsaturated fatty acids, and small particle lipids on satiety, satiation and perceptions of these. Acute research refers to studies which examine the transient effect of dietary lipids, usually a single bolus, whereas chronic adaptation refers to the study of a dietary lipid administered over two or more days. Studies were included that focused on satiety, satiation, perceived satiety or satiation (i.e visual analogue scales) or included elements that allowed for speculation into the effects of satiety

99 (i.e. energy intake). This allowed for discussion into the potential role of a lipid where limited research is currently available. Due to the production of SCFA in the gut, both 'direct' and 101 'indirect' studies are included; the direct administration of SCFA in a vehicle, or indirectly via 102 insoluble fibre which is fermented in the gut. Where possible, human studies are included, but 103 where mechanistic data in human studies are missing, animal studies are discussed. 
Medium-Chain Triglycerides (MCT) are triglycerides (esters derived from glycerol and three fatty acids) with fatty acid chain lengths of 6-12 carbon atoms. These include: capronic acid (C6:0), caprylic acid (C8:0), capric acid (C10:0) and lauric acid (C12:0). Along with synthetically produced oils, MCTs are found naturally in coconut oil, palm kernel oil, and a small amount in dairy fat 110 (Marten, Pfeuffer, and Schrezenmeir 2006). According to the 2014 report on nutrient intake in the 111 U.S, approximately $1.8 \%$ of all fat is MCFA (Agriculture 2014). However, due to a growing global popularity for coconut oil, this is likely to have increased.

\section{Mechanisms of Satiety}

115 MCT have been proposed to affect satiety by a number of mechanisms which may be cumulative. 116 Outlined below are some of the possible mechanisms.

\section{Absorption}

In 1951, Bloom, Chaikoff, and Reinhardt (1951) tested absorption rates of different ${ }^{14} \mathrm{C}$ labelled acids and found that lauric acid and capric acid (both medium chain fatty acids) are transported via the portal venous system, unlike long-chain triglycerides (LCT) which are transported by the lymphatic system. This method of absorption is faster and more efficient than triglycerides with a longer chain. Further, the esterification of MCT is limited, resulting in high levels of oxidation to the point of MCT behaving more like glucose than fat (Marten, Pfeuffer, and Schrezenmeir 2006). The results of Van Wymelbeke and colleagues (Van Wymelbeke, Louis-Sylvestre, and Fantino 2001) and Rolls et al. (Rolls et al. 1988) indicate pre-absorptive mechanisms pertaining to the rapid rate of absorption of MCT. Where LCT result in two 'peaks' of absorption; that being at the initial point of ingestion and a second delayed peak at the beginning of the next meal (Fielding et al. 1996; Evans et al. 1988; Cohn et al. 1988), MCT are fully absorbed at the point of ingestion. Therefore, MCT may contribute to satiation by this 'full absorption' mechanism. 
132 Fatty acid oxidation has been linked with increased satiety (Langhans and Scharrer 1987; Friedman 133 et al. 1999). MCT may have an anorexigenic effect through the concomitant production of ketones 134 that is a result of increased acetyl-CoA influx (Tsuji et al. 2001). Ingestion of MCT has been shown 135 to lead to increased concentrations of the ketone body $\beta$-hydroxybutyrate (Page et al. 2009), which 136 is thought to suppress appetite (Laeger, Metges, and Kuhla 2010; Scharrer 1999). The increase in 137 ketone bodies provides a substrate for energy, thereby sparing glucose (Zhang et al. 2013) and 138 decreasing food intake (Mayer 1953).

\section{Satiety Hormones}

141 Few papers have examined the response of these satiety hormones to MCT consumption (Maas et 142 al. 1998; Barbera et al. 2000; M-P St-Onge et al. 2014). Cholecystokinin (CCK) was the first gut 143 hormone found to influence satiety (Gibbs, Young, and Smith 1973). Lipid ingestion is linked to the 144 secretion of CCK, however this is dependent on the fatty acid chain length. The majority of MCT 145 do not lead to increased CCK levels (McLaughlin et al. 1999; Beglinger et al. 2010). However, in a 146 study by McLaughlin and colleagues (McLaughlin et al. 1999) CCK was released after either 147 emulsions of capric $(\mathrm{C} 10)$ or lauric $(\mathrm{C} 12)$ acid were infused into the gut of healthy volunteers. The control lipid in that study was Tween 80 mixed with a phosphate-buffered saline, which also 149 increased CCK secretion above baseline, meaning that the increase observed by C10 was not 150 significant. Feltrin and colleagues (Feltrin et al. 2004) aimed to address this limitation by using an 151 appropriate control and found that both $\mathrm{C} 12$ and $\mathrm{C} 10$ lead to increased CCK release, although the 152 magnitude of this increase was greater with C12. Further, C12 significantly decreased perceptions 153 of hunger, desire to eat, and prospective food consumption as well as energy intake at an ad libitum 154 buffet meal, whereas C10 did not. This suggests that even though some fatty acids with chain 155 lengths below 12 cause secretion of CCK, this is unlikely to affect appetite sensation. Multiple 
studies confirm that fatty acids with chain lengths of 12 and above are able to stimulate CCK, whereas chain lengths of 10 and below are not as effective (D Matzinger et al. 2000; J. T. McLaughlin et al. 1998; Feltrin et al. 2007, 2006; Feinle et al. 2001; Lal et al. 2004; French et al. 2000). Furthermore, despite initial findings suggesting otherwise (Hildebrand et al. 1990), CCK receptor antagonist studies indicate no role of CCK in fat induced satiety (Drewe et al. 1992). Despite the controversial role of CCK, it is still widely reported that CCK is a mediator of fatrelated satiety, through a delaying of gastric emptying (Liddle et al. 1986; Daniel Matzinger et al. 1999) by modulation of antropyloroduodenal motility (Feltrin et al. 2004), and a reduction of the capacity that can be tolerated in the upper gastrointestinal (GI) tract (Lal et al. 2004); processes which rely on the digestion of triglycerides into free fatty acids (Feinle et al. 2001; D Matzinger et al. 2000; Feinle et al. 2003; Pilichiewicz et al. 2003). Therefore as MCT do not require bile salts, secreted by CCK, for emulsification (McLaughlin et al. 1999), this could explain the lack of CCK response by shorter chain fatty acids. Despite this, MCT do seem to have appetite-suppressing effects, which are independent of CCK.

PYY is a 36 amino acid peptide belonging to the pancreatic polypeptide family, and its secretion is initiated by the sensing of nutrients, primarily protein (Batterham et al. 2006) and fat (Aponte et al. 1985; Pironi et al. 1993), in the GI lumen. Its anorectic effect has been demonstrated via peripheral administration of $\mathrm{PYY}_{3-36}$, which increases c-fos expression in the arcuate nucleus (ARC); and direct injection into the ARC inhibits food intake in rats and mice (Batterham et al. 2002; Riediger et al. 2004). After administering intraduodenal infusions of LCFA (corn oil) or MCT (56\% octanoic acid and 43\% decanoic acid), Maas et al. (Maas et al. 1998) found that MCT did result in PYY secretion, but not to the same extent as LCT. However, the caloric load of each infusion differed; $11.6 \mathrm{~kJ} \cdot \mathrm{min}$ from MCT and $22.7 \mathrm{~kJ} \cdot \mathrm{min}$ from LCFA which may have affected the potential for 
181 (Feltrin et al. 2007). It must be noted that CCK is a potent stimulator of PYY secretion (Marie182 Pierre St-Onge and Jones 2002), which could explain the weaker release of PYY by MCT. To date 183 no study has investigated MCT alongside PYY receptor antagonists, which could provide 184 conclusive information as to the effects of MCT on PYY release (St-Onge et al. 2014).

185 A more recent pilot study in overweight men investigated MCT ingested orally (as opposed to these 186 aforementioned studies which utilised duodenal infusions) on a variety of gut peptide hormones, 187 and found that, compared to LCT, MCT did not affect total ghrelin or GLP-1; but leptin and PYY 188 concentrations remained higher after the MCT meal (St-Onge et al. 2014). However, correlations 189 between these results and food intake at the ad libitum meal provided were opposite to the expected 190 direction, suggesting that the MCT suppression of food intake is not mediated by gut peptide 191 hormones. While these results do not appear to show a link between gut peptides and MCT driven 192 satiety, there is clearly more work to be done to confirm this.

\section{Other Considerations}

195 MCFA are considered unpalatable, and if initially digested in the mouth MCT may play a role in 196 sensory specific satiation (Clegg 2010). As well as their unpalatability, MCT have been shown to 197 cause GI distress, including vomiting and cramping (Jeukendrup et al. 1998; Goedecke et al. 2005). 198 This has been shown at high dosages of up to 85g, which are not typically used in appetite research; 199 more so sports performance (Jeukendrup et al. 1998). Infusion studies have reported greater nausea 200 after LCT than MCT (Barbera et al. 2000; Feinle et al. 2001), which is not supported by more 201 recent findings that nausea was greatest after a breakfast containing MCT (Coleman, Quinn, and 202 Clegg 2016). Regardless, this must be considered to ensure that any effects on satiety are not a 203 result of GI distress. 
Acute studies examining the effect of MCT on satiety and energy balance appear to have equivocal

207 findings. Some studies have found reductions at ad libitum meals following intake of MCT (Rolls et

208 al. 1988; Van Wymelbeke, Louis-Sylvestre, and Fantino 2001; Van Wymelbeke et al. 1998);

209 whereas others have reported no effect (Barbera et al. 2000; Poppitt et al. 2010). There are

210 limitations in several studies reporting no effect of MCT on satiety which suggests there is potential

211 for MCT to increase satiety. In the first study to investigate the effect of MCT on satiety in humans,

212 Rolls et al. (1988) administered three doses of either MCT or LCT (100, 200 and $300 \mathrm{kcal})$ in

213 beverage form and examined the effect on food intake at an ad libitum meal in dieters and non-

214 dieters. In dieters, they found no consistent change in intake. However, in non-dieters there was an

215 overall decrease of $\sim 14 \%$ in energy intake after MCT, and this was dose-dependent. Similarly, Van

216 Wymelbeke et al. (1998) found that MCT led to decreased intake at lunch when it was added to a

217 carbohydrate breakfast. Furthermore, in a later study by the same research group, there was

218 decreased intake at dinner after an MCT lunch when compared to a lunch with either LCT,

219 carbohydrate or a fat substitute (Van Wymelbeke, Louis-Sylvestre, and Fantino 2001). However,

220 Poppit et al. (2010) report no influence of MCT on perceived satiety after 18 healthy men

221 consumed high-fat breakfasts containing short-chain triglycerides, MCT or LCT. This could be

222 explained by the small dose of MCT in that study $(10 \mathrm{~g})$, whereas previous studies have observed

223 significant results with doses of $20 \mathrm{~g}$ or more (St-Onge et al. 2014; Rolls et al. 1988; Van

224 Wymelbeke, Louis-Sylvestre, and Fantino 2001; Van Wymelbeke et al. 1998).

226 As aforementioned, adverse effects related to MCT ingestion may confound any purported satiety

227 effects. Therefore, this must be either considered when analysing results or, preferably, when

228 designing the vehicle for the lipids. The studies of Poppit and colleagues (2010) and Van

229 Wymelbeke and colleagues (1998) both administered visual analogue scales to examine if there

230 were any subjective sensory differences between the meals provided and found that there was no 
231 difference, concluding that any effects were not related to palatability. A later study by Van 232 Wymelbeke's group (Van Wymelbeke, Louis-Sylvestre, and Fantino 2001) along with the study by 233 Rolls' research group (Rolls et al. 1988) included a pre-test where palatability of the test meals were 234 assessed; participants who registered low palatability scores were excluded in Rolls' study, whereas 235 the preliminary screening indicated participants were unable to distinguish between the breakfasts 236 in the study by Van Wymelbeke.

\section{Effects on satiety of chronic consumption of medium chain triglycerides}

239 There are few long-term studies reporting the effects of MCT on satiety, though many have studied 240 weight loss effects primarily through diet-induced thermogenesis. However, this is outside the 241 scope of this review. Krotkiewski (2001) examined extreme hypocaloric diets combined with either 242 MCT or LCT in overweight women. Weight loss was accelerated in the MCT group for the first two 243 weeks; however this decreased in weeks 3 and 4. This pattern was also observed in perceived 244 appetite and satiety, as after the first two weeks perceived appetite was lower at all time points and 245 perceived postprandial satiety was higher. The difference between the groups diminished by week 246 4, perhaps indicating an adaptation to chronic MCT intake. However, it must be noted that the 247 amounts of each fat provided in this study were very low (9.9g of MCT and $8.8 \mathrm{~g}$ of LCT).

248 Therefore if MCT has an effect at such low doses there is a rationale to increase the dose after the 249 initial adaptation has taken place. The results of this study (Krotkiewski 2001) show some exciting 250 potential as the decreased feelings of hunger may aid weight loss program adherence by reducing 251 dropout rates. 


\section{Conjugated linoleic acid}

253 Conjugated linoleic acid (CLA) is the name of a family of stereo and positional isomers of 254 octadecadienoic acid (linoleic acid), meaning isomers with the same formula and constitution but 255 different structures. 'Conjugated' refers to the conjugated double bonds, in that they are only 256 separated by one single bond. Of the 24 isomers of CLA (Kreider et al. 2010), the most commonly 257 examined in research are the cis-9, trans-11 CLA isomer, and the trans-10, cis-12 CLA isomer 258 (Campbell and Kreider 2008). The richest sources of these isomers are meat and dairy derived from 259 ruminants, of which approximately $90 \%$ is the cis- 9 , trans- 11 isomer and the remaining $10 \%$ is the 260 trans-10, cis-12 isomer (Mushtaq, Heather Mangiapane, and Hunter 2010; Kennedy et al. 2010). 261 Commercially available CLA typically contain approximately equal amounts of the cis-9, trans-11 262 and the trans-10, cis-12 isomers (Hargrave et al. 2002; Norris et al. 2009).

Mechanisms of Satiety

CLA effects on body weight and body composition have been widely reported (Blankson et al. 266 2000; Belury, Mahon, and Banni 2003; Gaullier et al. 2007, 2005). CLA is thought to reduce the 267 size of adipocytes through stimulation of pro-inflammatory cytokines such as TNF $\alpha$ (tumour 268 necrosis factor $\alpha$ ) and by the inhibition of PPAR $\gamma$ (peroxisome proliferator-activated receptors) 269 receptors by inhibiting adipocyte differentiation (Salas-Salvadó, Márquez-Sandoval, and Bulló 270 2006; Cawthorn and Sethi 2008). The trans-10, cis-12 isomer is reported to exert the most anti271 adipogenic effects through decreased expression of genes which regulate triglyceride storage and 272 transport of fatty acids (Brown and McIntosh 2003).

274 Although CLA has received little attention to date in relation to satiety, it does also have the 275 potential to reduce energy intake. Despite many not human studies specifically examining food 276 intake following CLA consumption, various animal studies have shown a decrease in intake after 
administration of CLA (Cao et al. 2007; Hargrave et al. 2002; Miner et al. 2001; Santora,

278 Palmquist, and Roehrig 2000; Yeonhwa Park et al. 1997; R Dugan et al. 1997), although some 279 studies found no effect (Tsuboyama-Kasaoka et al. 2000; DeLany et al. 1999; Wong et al. 1997). 280 Furthermore, even when decreased food intake was observed, the reductions do not completely 281 explain decreases in body fat (Shelton et al. 2012; Hargrave et al. 2002; Y. Park et al. 2007; Miner 282 et al. 2001), suggesting favourable changes in body composition are independent of appetite 283 control.

Despite a lack of studies specifically examining CLA and satiety, it is possible to discuss the potential link between the two. The glucostatic theory of appetite, developed by Mayer in the 1950s (Mayer 1953), proposed the presence of glucose receptors in the brain which respond to a fluctuation in glucose levels. Therefore, a drop in blood glucose level promotes an increase in hunger, and an increase in blood glucose (after exogenous carbohydrate ingestion) promotes the onset of satiation, due to the fact that glucose is the primary fuel for the central nervous system, and so it is tightly regulated in order to prevent hypoglycaemia (De Graaf et al. 2004; Campfield et al. 1996). CLA has been shown to increase lipolytic activity (Yeonhwa Park et al. 1997, 1999; Choi et al. 2000; Pariza, Park, and Cook 2001), which potentially may spare glucose oxidation and act as a

Leptin is a satiety-promoting hormone which is released by white adipose tissue (Perry and Wang 2012). Leptin has been shown to inhibit orexigenic neuropeptide Y (NPY) and agouti-related peptide (AgRP) co-expressing neurons (Sahu 2003), meaning that the centre of the hypothalamus which promotes hunger is inhibited. Increased body fat is associated with increased leptin circulation (Myers, Cowley, and Unzberg 2008), whereas reduced sensitivity to leptin has been 
shown to play a role in obesity, and can potentially be a strong driver of metabolic syndrome (PazFilho et al. 2009; J. M. Friedman and Halaas 1998). Medina et al. (Medina 2000) observed a decrease in leptin that was significant at 7 weeks of CLA supplementation but returned to normal in the final 2 weeks. There was no effect on energy intake or body mass index (BMI) between baseline and at the end of the study, suggesting CLA decreased leptin levels independently of body fat levels. Gaullier et al. (2005) also observed decreases in circulating leptin and energy intake after 24 months of supplementation with both triglyceride and free fatty acids forms of CLA. These findings suggest that, in the absence of leptin resistance, increased levels of leptin decreases energy intake (Klok, Jakobsdottir, and Drent 2007), indicating a potential mechanism for CLA-mediated satiety.

310 Conversely, Iwata et al. (2007) reported an increase in leptin concentrations after CLA but no 311 concurrent decrease in energy intake. However, leptin concentrations also increased in the placebo 312 group, again with no change in energy intake indicating the changes in leptin are likely to be 313 unrelated to CLA intake. Increased leptin concentrations was also reported after 314 intracerebroventricular administration of CLA in rats, which decreased expression of NPY and 315 AgRP and consequently feed intake (Cao et al. 2007). However, another study rejected the idea that 316 CLA affects neuropeptide expression in the hypothalamus, as no CLA isomers were identified in 317 the brain (Shelton et al. 2012). CLA did significantly decrease feed intake, but the authors suggest 318 CLA may have altered serum hormone levels as opposed to a central mechanism.

\section{Acute intake of conjugated linoleic acid on satiety}

321 To date, there is only one study which has examined the effect of CLA on food intake (Coleman, 322 Quinn, and Clegg 2016). In that study, participants consumed a smoothie drink containing either 323 vegetable oil (as the control) CLA or MCT after which they consumed an ad libitum sandwich 324 lunch, which was provided upon request. Both test fats elicited non-significant decreases at the ad libitum lunch, and intake throughout the rest of the day (and therefore overall energy intake) was 
significantly lower following CLA and MCT compared to the control. CLA resulted in the longest

327 time-to-meal request. More research is required to examine further the effectiveness of CLA as a 328 method of reducing food intake and enhancing satiety.

\section{Effects on satiety of chronic consumption of conjugated linoleic acid}

331 Where few studies have examined CLA in the short term, there are many studies examining its 332 effects as a long-term dietary intervention for improving body composition and reducing body 333 weight. An excellent meta-analysis of this topic was conducted by Onakpoya and colleagues 334 (Onakpoya et al. 2012). We have included papers which allowed for speculation as to the satiety 335 effects of CLA.

336 The majority of studies have not shown any significant impact of CLA on energy intake, indicating 337 that there are satiating effects associated with CLA consumption (Cornish et al. 2009; Gaullier et al. 338 2005; Iwata et al. 2007; E. V Lambert et al. 2007; Medina et al. 2000; Norris et al. 2009; Wanders 339 et al. 2010). Cornish et al. (2009) investigated the combination of mixed isomer CLA, creatine and 340 whey protein versus creatine plus placebo oil, and the placebo oil alone. Whereas there were 341 significant increases in lean mass and strength with all three supplements combined, there was no 342 difference in dietary intake between groups during the intervention period. The findings of Pinkoski 343 et al. (2006) corroborate this, as lean mass was increased to a greater extent after 7 weeks of mixed 344 isomer CLA supplementation alongside resistance exercise compared to a placebo. However, there 345 was no change in self-assessed energy intake between baseline and 7 weeks between the two 346 groups. Norris et al. (2009) reported reductions in BMI, in overweight postmenopausal women with 347 type 2 diabetes after 36 weeks of supplementation with $6.4 \mathrm{~g} / \mathrm{d}$ of mixed isomer CLA. Interestingly, 348 the decline in BMI had not yet reached a plateau, and there may have been further decreases had the 349 study period been longer. This study also showed no difference in energy intake over the study period, which was assessed via 3-day diet diary 4 times over the intervention period. These studies 
351 indicate that CLA may be beneficial for improving body composition and promoting weight loss; 352 however these changes are achieved independently of satiety. Nonetheless, this is an inference 353 based on self-reported diet diary data and satiety was not the primary measure of the 354 aforementioned studies, and so more work is required to confirm this.

355 In contrast, Kamphuis et al. (2003) found mixed isomer CLA dose-dependently increased feelings 356 of fullness and decreased feelings of hunger after 13 weeks of supplementation with a low (1.8g) 357 and high (3.6g) dose. This did not affect energy intake at breakfast, although as this was the only 358 meal analysed it is possible that intake may have been affected during the rest of the day. Watras et 359 al. (2007) reported that mixed isomer CLA led to decreased weight gain over a 6 month period 360 compared to a placebo. This was especially true during the winter holiday period, when the placebo 361 trial subjects increased their energy intake yet there was no change in energy intake in the CLA 362 group indicating that the CLA may have suppressed food intake.

364 CLA does appear to be promising in the management of obesity and as a supplement to improve 365 body composition (Blankson et al. 2000; Belury, Mahon, and Banni 2003; Gaullier et al. 2007, 366 2005); however, this appears to be achieved without increasing satiety. Further work is required 367 before conclusions can be drawn, especially studies focusing on satiety and not body composition. 368 It is also noteworthy to mention that there have been some deleterious effects reported with CLA 369 ingestion, particularly insulin resistance (Risérus, Berglund, and Vessby 2001; Medina et al. 2000; 370 Smedman and Vessby 2001), which seems intuitive given the key role of leptin in glucose 371 homeostasis (Denroche, Huynh, and Kieffer 2012) and the aforementioned reported decrease of 372 leptin by CLA. An early review by Wahle and colleagues (Wahle, Heys, and Rotondo 2004) 373 suggested that more research is warranted in order to conclude whether CLA is truly beneficial or 


\section{Short-chain fatty acids}

Short-chain fatty acids (SCFA) are carboxylic acids which are aliphatic, ranging from two carbons to four carbons in length. SCFA are made in the colon through bacterial fermentation when nondigestible carbohydrates pass through the upper GI tract and reach the large intestine (Byrne et al. 2015). The three main SCFA created are acetate (C2), propionate (C3) and butyrate (C4) in a ratio of approximately 60:20:20. There are also some dietary sources of SCFA such as sourdough bread, vinegar and vinegar-based products such as pickles, and finally some cheeses and other dairy products (Darzi, Frost, and Robertson 2011).

\section{Mechanisms of Satiety}

\section{Central control of appetite}

There are a number of potential mechanisms by which SCFA may influence satiety. These involve an increase in circulating anorexigenic hormones (Cani et al. 2006; E. S. Chambers et al. 2015; Nilsson et al. 2013) and a decrease in circulating ghrelin (Parnell and Reimer 2009). Acetate has also been shown to cross the blood-brain barrier and be taken up by the brain, specifically by the hypothalamus in both mice (Chambers et al. 2015) and humans. Appetite may be suppressed by SCFA via this mechanism, as the anorectic signal in the ARC produces increased expression of proopiomelanocortin (POMC) and reduced expression of AgRP (Frost et al. 2014). AgRP, along with NPY, is a potent stimulator of food intake, whereas POMC, along with cocaine- and amphetamine-regulated transcript (CART) provides a tonic anorexigenic signal to suppress appetite and food intake (Cone 2005; Wynne et al. 2005; Morton and Schwartz 2006; Millington 2007). SCFA may also be involved in a similar central control of feeding via intestinal gluconeogenesis (IGN). It has been shown that both butyrate and propionate stimulate IGN (Bienenstock, Kunze, and Forsythe 2015a; De Vadder et al. 2014). This is sensed by sodium-glucose cotransporters (possibly SGLT3) in the portal vein which send an afferent nervous signal to decrease food intake 
400 (Delaere et al. 2013). Butyrate has been shown to increase directly expression of 401 phosphoenolpyruvate carboxykinase $1(P C K 1)$ and glucose-6-phosphatase catalytic subunit $(G 6 P C)$ $402-$ genes involved in the regulation of IGN -2 to 3-fold. In contrast, propionate does not directly 403 stimulate IGN genes, but binds to FFA3, which sends signals to the parabrachial and paraventricular 404 nuclei in the brain; driving a reflex arc to induce IGN in the gut (De Vadder et al. 2014).

Satiety Hormones and Gastric Emptying

407 The SCFA receptors FFA2 and FFA3 have been shown to be co-expressed in L-cells which release 408 glucagon-like peptide-1 (GLP-1) and PYY (Byrne et al. 2015). Indeed, it has been shown that 409 propionate stimulates the release of GLP-1 and PYY via FFA2 (Psichas et al. 2014). These findings 410 are corroborated by animal models which show that GLP-1 concentrations are decreased in FFA2 411 knockout mice (Tolhurst et al. 2012) and likewise with PYY in FFA3 knockout mice (Samuel et al. 412 2008). The satiating effects of PYY have already been mentioned, and GLP-1 similarly enhances 413 satiety via a delay in gastric emptying (Flint et al. 1998; Shah and Vella 2014). GLP-1 receptors 414 appear in areas in the central nervous system which are involved in feeding control, such as the 415 paraventricular nucleus (PVN), the ARC and on POMC neurons (Dailey and Moran 2013; De Silva 416 and Bloom 2012).

417 The satiating properties of propionate have also been attributed to gastric emptying (Liljeberg and 418 Björck 1996). Colonic contractile activity has been shown to be reduced in rats after SCFA infusion 419 to the colon (Squires et al. 1992), but a more recent study showed no effect of colonic infusion on 420 contractile activity in human volunteers (Jouët et al. 2013). Liljeberg and Björck (1996) found 421 greater perceived satiety linked to slower gastric emptying after SCFA ingestion. 
424 Darzi and colleagues (Darzi, Frost, and Robertson 2012) attribute the satiating effects of SCFA to 425 the hedonic unpleasantness of propionate rather than post-absorptive mechanisms. They found no 426 effect of bread containing a small amount of propionate, which was more acceptable and did not 427 cause nausea, lending credence to this hypothesis. They concluded that any effects seen may be due 428 to the palatability of orally administered SCFA, and do not support a role in appetite regulation 429 (Darzi, Frost, and Robertson 2011). Future studies need to mask these unpleasant characteristics of 430 the SCFA.

431 This review aims to discuss dietary lipids and satiety. However it must be briefly mentioned that 432 studies in mice and rats have shown that fermentable carbohydrates (such as inulin and 433 fructooligosaccharides [FOS]) lead to production of SCFA in the large intestine (Ten Bruggencate 434 et al. 2005; Arora et al. 2012), and this may also affect satiety. Long-term ingestion of soluble fibre 435 may also lead to increased satiety due to increased proliferation of GLP-1 producing L-cells (Kaji et 436 al. 2011; Kuwahara 2014). Kuwahara (2014) explains how this can only occur after long-term 437 ingestion of FOS, as fermentation can take a number of days to occur and only then can this affect 438 GLP-1 production. This may not manifest in changes in short-term satiety, but possibly in long-term 439 energy homeostasis.

$441 \quad$ Acute intake of short-chain fatty acids on satiety

442 As outlined above studies examine SCFA via two methods: direct administration (such as through 443 the use of vinegar (Kondo et al. 2009; Ostman et al. 2005)) or indirectly (through the use of fibre 444 (Nilsson et al. 2013) and fermented dairy beverages (Ruijschop, Boelrijk, and te Giffel 2008)). 445 Ruijschop et al. (2008) examined the use of a dairy beverage fermented with Lactobacillus 446 acidophilus and Propionibacterium freudenreichii on satiety and food intake, and found greater 447 feelings of satiety when compared to a placebo although there was no corresponding change in food 448 intake. This is the only study to date, to our knowledge, which has investigated cultured propionic 
acid bacteria in a dairy beverage on satiety. Despite the fact there was no effect on energy intake, it would be apposite to conduct more studies to fully elucidate its potential.

451 A dose-response study investigating different amounts of acetate in the form of vinegar added to a 452 bread meal found that there is a linear relationship between subjective satiety and acetate ingestion 453 (Ostman et al. 2005). Similarly, Hlebowicz et al. investigated different breads soaked in acetic acid 454 (white, wholemeal or wholegrain) and compared them to an un-soaked white bread control 455 (Hlebowicz et al. 2008). While the wholegrain/acetate combination led to the greatest subjective 456 satiety, these results must be treated with caution as there was no wholegrain control (i.e. not 457 soaked with the acetate). Hence it is difficult to ascertain whether the wholegrain bread or the 458 acetate influenced satiety in that study. Conversely, some studies have failed to link SCFA to 459 satiety. Mettler et al. found no significant effect of adding either acetate, cinnamon, both, or neither 460 to a rice pudding meal on subjective satiety (Mettler, Schwarz, and Colombani 2009). Poppit et al. 461 (2010) also found no effect of short-chain triglycerides from soft fraction milk fat on subjective feelings of hunger or energy intake.

463 In the review by Darzi and colleagues discussing the role of SCFA in appetite regulation (Darzi, 464 Frost, and Robertson 2011), the authors discuss unpublished data on which they conducted pooled 465 correlations. According to the authors, these findings suggest that acetate-containing vinegar may 466 influence satiety through palatability effects rather than any mechanistic/physiological effects of 467 SCFA. More recently, the same group conducted a series of experiments investigating the satiety 468 effects of vinegar alongside a study investigating the orosensory properties of a vinegar containing 469 beverage (Darzi et al. 2014). These studies showed that tolerability of vinegar, as opposed to 470 palatability per se, is the cause of nausea after ingestion. This is due to the significant increase in 471 perceived nausea after consuming the test drink but no difference when the drink was sham fed (i.e. held in the mouth and then expectorated). These findings discredit the use of vinegar as a satiety- 
enhancing product, as poor tolerability and nausea are possibly the main causes of reduced intake, rather than the physiological effect of activating FFA2 and FFA3.

Despite systematic reviews examining both acute and chronic randomised control trials concluding that fibre only yields small satiety effects (Wanders et al. 2011) and the majority of studies failing to find significant effects (Clark and Slavin 2013), fibre may promote satiety by delaying gastric 478 emptying and leading to a greater release of satiety hormones (Chambers, McCrickerd, and 479 Yeomans 2015). Nilsson et al. (2013) reported that feeding healthy participants an evening meal 480 consisting of brown beans - which contain large amounts of indigestible carbohydrates - increases 481 circulating PYY and decreases circulating ghrelin after a standard breakfast meal. This was 482 attributed to propionate, as concentrations were significantly increased after the brown bean meal 483 compared to the control. However, the results of this study could also be due to other characteristics 484 of fibre and not SCFA exclusively. Tarini and Wolever (2010) found concentrations of plasma 485 GLP-1 were increased and serum ghrelin were decreased after $24 \mathrm{~g}$ of inulin was added to a test 486 drink; effects attributed to increased colonic SCFA production. Considering that the daily reference 487 value for fibre is $30 \mathrm{~g} \cdot$ day, this is a large bolus of fibre to consume in a single sitting; but it does 488 demonstrate the potential for fermentable fibre to mediate satiety, possibly through increased SCFA 489 levels in the gut.

\section{Effects on satiety of chronic consumption of short-chain fatty acids}

491 Current knowledge on SCFA is limited as the majority of studies conducted to date are in animal models, with more studies in human participants required to elucidate the effects and mechanisms of SCFA on energy expenditure, intake, and balance. Kondo et al. (2009) conducted the first study

494 to investigate the effect of SCFA (in the form of acetic acid present in vinegar) on body 495 composition. This double-blind parallel study administered beverages with either no vinegar 496 (control) or a low or high dose (15 and $30 \mathrm{ml}$, respectively) of cider vinegar for 12 weeks. They 
found that body composition was improved in a dose-dependent manner, showing that acetic acid,

498 in the form of vinegar, can beneficially alter body composition, fat mass, and body weight.

499 However, there were no differences between any of the groups during the supplementation period 500 for energy intake, macronutrient composition of foods eaten or physical activity. From this, we may 501 infer that the beneficial effects of orally ingested acetate, the most abundant of the SCFA, are not 502 linked to satiety. Conversely, in a study by Cani et al. (2006) two 8g portions of oligofructose were 503 taken at breakfast and dinner for two weeks. Subjective satiety after an ad libitum breakfast was 504 significantly higher than baseline after the supplementation and intake was lower at the meal. Intake 505 was also lower at the ad libitum lunch provided, but not at dinner, corresponding to a significant 506 decrease in energy intake throughout the whole day of approximately $5 \%$ after oligofructose intake.

507 Despite discussing the fermentation of fibres at length and commenting on SCFA production, this 508 paper, unfortunately, did not measure SCFA production, which would have allowed for a link 509 between satiety and SCFA. SCFA concentrations, however, were reportedly increased after 6 weeks 510 of oligofructose supplementation in another study, which corresponded to decreased energy intake 511 and reported hunger, as well as increased PYY (Daud et al. 2014). Similarly, Chambers et al. 512 measured the release of GLP-1 and PYY from L cells in vitro and found that SCFA led to 513 significant increases in hormone release above basal levels (Chambers et al. 2015). That group 514 produced a novel ester which bound propionate to inulin by an ester bond. This allowed delivery of 515 propionate to the gut as inulin which was fermented by colonic fermentation, thereby releasing the 516 propionate. In a 24 -week follow-up supplementation study in 49 volunteers, $10 \mathrm{~g}$ of propionate per 517 day led to significant reductions in energy intake of $14 \%$ compared to the control group. This 518 decrease was attributed to the increased stimulation of GLP-1 and PYY that the authors found in the 519 in vitro part of the study. Similarly, Freeland et al. (2010) reported increased plasma butyrate and 520 increased GLP-1 release after chronic intake of fibre. This may outline the mechanisms behind 
521 SCFA and satiety, although these results were only observed after 9 months of intake (20g of 522 fibre-day over baseline intake).

523 Clearly, the literature surrounding SCFA is far from unequivocal, although it is possible that the 524 specific SCFA may exert different effects on satiation and body composition. This is an avenue for 525 future work. 


\section{Diacylglycerol}

527 Diacylglycerol (DAG) is a glyceride which consists of two fatty acids on a glycerol backbone and naturally occurs in small amounts in cooking oils; from $0.8 \%$ in rapeseed oil to $5.5 \%$ in olive oil and 9.5\% in cottonseed oil (Rudkowska et al. 2005; Flickinger and Matsuo 2003; D'Alonzo, 530 Kozarek, and Wade 1982). In 1999, the Kao Corporation in Japan introduced DAG oil which 531 contained over 80\% DAG and sold over 70 million bottles between then and 2003 (Flickinger and Matsuo 2003).

\section{Mechanisms of Satiety}

\section{Substrate Oxidation}

Chronic studies examining the effects of DAG on weight loss have attributed the decrease in adipose tissue to greater levels of $\beta$-oxidation (Maki et al. 2002; Nagao et al. 2000), although to the authors' knowledge only one study has directly measured this (Kamphuis, Mela, and WesterterpPlantenga 2003). Scharrer and Langhans (1986) first established that inhibited fatty acid oxidation stimulates feeding, and since then hepatic fatty acid oxidation has been linked with hunger (Kahler, Zimmermann, and Langhans 1999). Therefore the decrease in appetite shown in the study by Kamphuis et al. (2003) could be attributed to the lipoprivic control of eating.

\section{Gastric Motility}

The transport and absorption of DAG are similar to medium-chain triglycerides, despite the fact it is mainly comprised of long-chain fatty acids. Long-chain fatty acids ( $\geq 12$ carbon atoms) slow gastric emptying - the rate of food leaving the stomach and entering the duodenum (Clegg and Shafat 2009) - to a greater extent than shorter chain fatty acids (Hunt and Knox 1968). It has been shown that gastric emptying is correlated with satiety, and therefore the longer food remains in the stomach the greater is the satiating effect (Bergmann et al. 1992; Geliebter 1988). Therefore it is possible 
that DAG may influence satiety through delayed gastric emptying, although this is only speculation as there are currently no studies which have investigated this.

Stoeckel et al. (2008) compared the effect of a high-fat beverage consisting mainly of DAG to a very low-calorie beverage on PYY release. Participants were divided into either high PYY release or low PYY release groups. In the high PYY group, the response was significantly higher after the DAG drink compared to the low-calorie drink, which also corresponded to decreased ratings of hunger. No other study to the authors' knowledge has reported PYY 'non-responders' and it is not currently known why this study found this. It is tempting to speculate an effect of DAG on PYY release; however without a control oil to compare it to it is impossible to say whether this response is similar to other long-chain oils.

\section{Acute intake of diacylglycerol on satiety}

As aforementioned, Kamphuis, Mela and Westerterp-Plantenga (2003) examined the effect of energy-balance diets for 4.5 days on substrate oxidation, energy expenditure, and subjective appetite when $40 \%$ of the fat provided was either DAG or TAG oil. On the fourth day, DAG oil intake was $33.0 \pm 2.3 \mathrm{~g}$ which provided $26.4 \pm 1.9 \mathrm{~g}$ of DAG, and on the fifth day, DAG oil intake was $22.2 \pm 1.4 \mathrm{~g}$ which provided $17.8 \pm 1.1 \mathrm{~g}$ of DAG. DAG oil led to decreased subjective hunger and increased subjective satiety, which was attributed to higher rates of $\beta$-oxidation. Participants were fed a prescribed amount in order to achieve energy balance, and so whether these subjective feelings would lead to changes in ad libitum intake is unknown. Given that the inhibition of fatty acid oxidation stimulates hunger (Langhans et al. 2011; Leonhardt and Langhans 2004), it is

574 possible that this increase in $\beta$-oxidation will have the opposing effect and prevent hunger, although 575 this requires further study. To the authors' knowledge, this is the only study to date which has 
576 investigated the role of DAG on appetite. Taking into account the potential for cumulative 577 mechanisms which could lead to enhanced satiety, this is an exciting avenue for further research.

\section{Effects on satiety of chronic consumption of diacylglycerol}

580 It has been repeatedly shown that chronic intake of DAG can lead to decreased body weight and 581 reduced accumulation of adipose tissue (Kawashima et al. 2008; Li et al. 2008; Yasunaga et al. 582 2004; Maki et al. 2002; Yamamoto et al. 2001; Taguchi et al. 2001). There are clearly some long583 term benefits associated with the intake of DAG, although this is outside the scope of the current 584 review; however, readers are directed to the meta-analysis of $\mathrm{Xu}$ et al. (2008). To the authors' 585 knowledge, no study to date has investigated chronic DAG intake on satiety specifically. Self586 reported diet diary data suggests that DAG has no long-term effect on satiety (Yamamoto et al. 587 2001) or can decrease energy intake but no more than a triacylglycerol control oil (Kawashima et al. 588 2008). Li et al. (2008) found that carbohydrate intake was decreased after 120 days of DAG 589 supplementation, but the decrease in total energy intake only approached significance $(P=0.08)$. It 590 is noteworthy to mention that the study by Kawashima and colleagues (2008) administered DAG oil 591 in an ad libitum protocol where participants merely swapped their normal cooking oil with DAG 592 oil. This is of particular importance as most studies administer lipids by adding extra lipid to food, 593 such as yoghurt (Kamphuis, Mela, and Westerterp-Plantenga 2003) or a beverage (Stoeckel et al. 594 2008), and so this ad libitum protocol has been shown to yield significantly positive effects without 595 administering set doses. This study also reported no differences in fasting ketone bodies after the 596 treatment period, which suggests the increase in hepatic fatty acid oxidation is transient. It would be 597 pertinent to investigate if there is increased postprandial $\beta$-oxidation after chronic DAG 598 supplementation to elucidate whether there is an added benefit to short-term intake. However, the 599 current evidence suggests that DAG supplementation does not increase satiety. 


\section{Omega-3 Polyunsaturated Fatty Acids}

601 Omega-3 (n-3) polyunsaturated fatty acids (PUFA) are essential fatty acids as they cannot be 602 synthesized de novo (Lorente-Cebrián et al. 2013). The main n-3 PUFA are eicosapentaenoic acid 603 (EPA, 20:5n-3) and docosahexaenoic acid (DHA, 22:6n-3) which are found in large quantities in 604 certain fish, such as mackerel, salmon, and sardines; therefore these are considered to be 'fish oils' 605 (Ackman 2008). Whereas $n-6$ PUFA possesses inflammatory properties by leading to the secretion 606 of the proinflammatory cytokine interleukin-1 and the leukotriene LTB $4, n-3$ PUFA are anti607 inflammatory and may help protect against inflammatory and autoimmune diseases (Simopoulos 608 2002). Research has shown positive effects of fish oil on cardiovascular diseases (Chowdhury et al. 609 2012; Ebrahimi et al. 2009), dyslipidaemia (Paniagua et al. 2011; Jiménez-Gómez et al. 2010) and 610 body composition (Bender et al. 2014), however few studies to date have investigated the effect of $611 n$-3 PUFA on satiety and food intake.

\section{Mechanisms of Satiety}

Central control of appetite

615 The endocannabinoid system is a complex system with various physiological roles, one of which is 616 the regulation of food intake (Pagotto et al. 2006). Lipids have diverse roles in the control of 617 appetite through this system, such as the orexigenic anandamide ( $N$-arachidonoylethanolamine, $\$ 18$ AEA) and the opposing anorexigenic oleoylethanolamide (OEA) (Lambert and Muccioli 2007; 619 Petersen et al. 2006). Levels of gut OEA are low during prolonged fasting and rise postprandially, 620 and OEA has been shown to suppress food intake in rats through peroxisome proliferator-activated 621 receptor $\alpha(\operatorname{PPAR} \alpha)($ de Fonseca et al. 2001; Fu J. et al. 2003). In contrast, anandamide has been 622 shown to increase appetite to the point of inducing over-consumption (Williams and Kirkham 623 1999). Wood et al. (2010) noted that DHA-enhanced mouse-chow led to decreased plasma 624 concentrations of both OEA and AEA, which may suggest a homeostatic mechanism in order to 
maintain energy balance. However, given that OEA can exerts its anorexigenic effects when

626 accumulating locally in the intestine without affecting plasma levels (Borrelli and Izzo 2009), this 627 requires further research for confirmation.

629 As briefly mentioned previously, the hypothalamus is the main centre of the brain for regulating 630 energy intake. In recent years, there has been emerging evidence that other areas of the brain are 631 involved with energy intake, such as mesolimbic dopamine system (Volkow, Wang, and Baler 632 2011). The controversial idea of categorising appetite as an addiction and obesity as a 633 neurobehavioral disorder has been proposed in recent years (Dagher 2009), and in this context, 634 obesity may be a result of the excess energy intake from the consumption of energy dense foods due 635 to their potent reward. Chalon (2006) found that the mesolimbic dopaminergic pathway was 636 overactive in rats with $n-3$ PUFA deficiency, and this could possibly manifest in changes in eating 637 behaviour due to its role in reward-seeking behaviours, such as the consumption of palatable foods. 638 Indeed, Cordeira et al. (2010) found that depleted brain-derived neurotrophic factor (BDNF) led to 639 increased intake of chow in mice due to modulation of the mesolimbic dopamine system. Further 640 research is required to investigate the link between $n$-3 PUFA and the mesolimbic system, but if 641 supplementation can suppress reward-seeking behaviour, it could be a useful tool for decreasing energy intake.

\section{Increasing appetite}

645 It is important to remember that not all individuals need to reduce their energy intake. Patients with 646 cancer can suffer from cancer anorexia-cachexia, the muscle wastage that occurs as a result of the 647 disease (Dodson et al. 2011). One of the complications of this condition is poor appetite, possibly 648 due to cytokine-inhibition of neuropeptide Y (Donohoe, Ryan, and Reynolds 2011). 649 Supplementation with $n-3$ PUFA can reduce the production of interleukin- 1 and interleukin- 6 
cytokines (Barber, Ross, and Fearon 1998). Therefore, supplementation with EPA may help combat

651 the loss of appetite associated with this condition. This suggests that there may be a role for $n-3$ 652 PUFA in overall energy intake regulation, managing both over- and under-consumption.

\section{Acute intake of omega-3 PUFA on satiety}

To the authors' knowledge, there are no studies to date which have investigated the acute effect of n-3 PUFA intake on satiety. $n$-3 PUFA appears to mediate its effects by increasing the phospholipid content of the cell membrane of EPA and DHA (Calder 2010), which occurs in a dose-dependent manner after supplementation (Rees et al. 2006). Therefore, there may be no benefit to satiety when n-3 PUFA are taken acutely. Some studies have found that $n$-3 PUFA ingestion can lead to mild side-effects, such as nausea (Bruera et al. 2003), and have an unpleasant taste (Damsbo-Svendsen, Rønsholdt, and Lauritzen 2013). These are factors which must be taken into consideration when studies assessing acute intake of $n$-3 PUFA on satiety are designed, as they may confound the results.

\section{Effects on satiety of chronic consumption of omega-3 PUFA}

666 Studies have measured the effect of $n$-3 PUFA in various chronic diseases, whereas the role of $n-3$

667 PUFA in satiety has received little attention. The current evidence is equivocal. Parra et al. (2008) examined the use of seafood diets and fish oil capsules on appetite in overweight and obese 669 participants who were already undergoing caloric restriction, and found that participants in the high $670 n-3$ PUFA groups reported increased fullness and decreased hunger and desire to eat after a test 671 meal, assessed by visual analogue scale after the evening meal, which was consumed in habitual conditions. However, it is difficult to conclude whether these effects are chronic effects from the supplementation and diet manipulation or acute effects from the test meals, as the test dinners 674 differed between groups (cod in the low n-3 group, salmon in the high $n-3$ group). This does 
675 indicate that the long-term intake is associated with appetite suppression, but more research is 676 needed to confirm this. Furthermore, this study did not measure pre-meal appetite sensations and 677 therefore the results must be interpreted with caution, as differences from baseline may have 678 affected the results. Damsbo-Svendsen et al. (2013) found that fish oil tablets were not as effective 679 as soybean tablets for increasing satiety, as they reported that postprandial fullness was increased 680 and desire to eat decreased after soybean supplementation for 3 weeks. However, the washout 681 period in this study was one week long, and this may not be enough to completely remove any 682 effects from the previous supplementation (Brown, Pang, and Roberts 1991; Hansen et al. 1998).

683 Interestingly, Bruera et al. (2003) found that appetite decreased in both an intervention group and a 684 control group. The aim of that study was to investigate whether $n$-3 PUFA can aid patients with 685 cachexia, which can manifest in symptoms such as weight loss and a reduction in appetite. 686 Unexpectedly, results from this study showed that appetite decreased in patients with cancer 687 cachexia, although it has been previously shown that supplementation with EPA can improve 688 appetite in these patients (Barber et al. 1999). Jatoi et al. (2004) examined the use of supplementing $6891.09 \mathrm{~g}$ of EPA and $0.46 \mathrm{~g}$ of DHA versus the appetite stimulating progesterone megestrol acetate, 690 and found no differences between the two (or a combination) in terms of appetite, as appetite 691 ratings increased in all three arms. Where this showed no benefit of EPA compared to megestrol, it 692 does show the ability of EPA to increase appetite in cachexia. Similar results have been found in 693 Yehuda et al. (2005) who reported that a mixture of $n-3$ and $n-6$ fatty acids led to increased 694 subjective appetite in those who suffered test anxiety compared to a placebo mineral oil. It was 695 again further corroborated by Zaid et al. (2012), who found that there was an increase in subjective 696 appetite ratings in children with leukaemia after 8 weeks of supplementation with $360 \mathrm{mg}$ EPA and $697240 \mathrm{mg}$ DHA daily. These results also indicate that $n-3$ may be useful in appetite control, but for 698 those who need to increase appetite and not for those undertaking a weight loss intervetion. 
699 Clearly, more research is needed in healthy volunteers and in a cohort attempting to lose weight. 700 Some of these studies have shown that n-3 PUFA supplementation can increase appetite in 701 inflammatory diseases (such as cancer cachexia), but, counterintuitively, they have also been shown 702 to be beneficial in weight loss as well. More research is needed to strengthen our understanding of 703 the role of $n-3$ PUFA in the modulation of appetite. 


\section{Small Particle Lipids}

705 Research into lipid droplets is a relatively new field, as it was believed until the early 1990s that 706 they were inert deposits (Suzuki et al. 2011). Lipids droplets consist of a core of lipids surrounded 707 by a phospholipid monolayer (Tauchi-Sato et al. 2002; Fujimoto and Parton 2011) and range in size 708 from $0.3 \mu \mathrm{m}$ to $20 \mu \mathrm{m}$ in various milks and infant formulas (Favé, Coste, and Armand 2004). Small 709 particle lipids (SPL) are created via fractionation.

\section{Mechanisms of Satiety}

Digestion

713 Smaller lipid droplets lead to increased emulsion surface area, meaning that fat hydrolysis will 714 increase, as lipase is active on the surface (Maljaars et al. 2012). Armand (Armand 2007) states that 715 as lipase is abundant, therefore a larger lipid/surface inter-surface area allows for extra binding. 716 Also, human pancreatic lipase is inhibited by large amounts of free fatty acids which accumulate at 717 the surface of lipid droplets; a greater surface area delays this inhibition, thereby increasing the 718 amount of hydrolysis (Armand et al. 1999; Patrick Borel et al. 1994). Increased rates of hydrolysis 719 may increase satiety by increasing fatty acid sensing in the small intestine (Maljaars et al. 2012). 720 Borel et al. (1994) conducted the first in vivo (in rats) study examining lipid droplet size and 721 digestion, and found that finer emulsions led to greater hydrolysis than coarser emulsions. These 722 findings were confirmed in healthy humans a few years later when emulsions were administered 723 intragastrically (Armand et al. 1999). Furthermore, CCK was more potently released with 724 emulsified LCT - with reduced droplet size - than non-emulsified LCT (Ledeboer et al. 1999).

726 The concept of the 'ileal brake' was first established in the mid-1980s and was shown to both 727 reduce jejunal motility (Spiller et al. 1984) and delay gastric emptying (Read et al. 1984). The ileal 728 brake has been shown to delay gastric emptying to a greater extent than the duodenal brake (Welch, 
729 Saunders, and Read 1985; Maljaars et al. 2012). This was confirmed in later studies by the 730 University Hospital Maastricht research group who showed that smaller lipid droplets led to 731 increased peptide secretion and satiety scores over larger droplets, but only when infused into the 732 ileum and not the duodenum (Maljaars et al. 2012). It must be noted that droplet size does also 733 appear to have an effect when administered to the duodenum, as Seimon et al. (2009) found that 734 infusion of lipids with a droplet size of $0.26 \mu \mathrm{m}$ led to greater stimulation of CCK, PYY and hunger 735 suppression, leading to decreased energy intake. However, it was also found in another study that 736 this was only apparent when fat is infused as compared to oral consumption of the same load 737 (Maljaars et al. 2011). However, intragastric infusions are not a feasible method of decreasing 738 energy intake.

\section{$740 \quad$ Acute intake of small particle lipids on satiety}

741 Fabuless $^{\mathrm{TM}}$ (previously Olibra ${ }^{\mathrm{TM}}$ ) is an emulsion comprised of palm oil and oat oil, produced by

742 DSM (Delft, the Netherlands). GI transit time has been shown to be delayed when Fabuless ${ }^{\mathrm{TM}}$ was 743 delivered intra-gastrically (Knutson et al. 2010). Early studies conducted at the University of Ulster 744 showed that this product decreased energy intake by an impressive $22-27 \%$ when compared to a 745 control fat in lean, overweight and obese subjects (Burns et al. 2002, 2001, 2000). These results 746 have, unfortunately, not been replicated (Smit et al. 2011; Smit et al. 2012; Chan et al. 2012), even 747 by the same research group (Logan et al. 2006). Smit and colleagues investigated the possible role 748 in the processing of the emulsion, and even with minimal processing (i.e. no shear and a maximum 749 temperature of $42^{\circ} \mathrm{C}$ ), there were effects on subjective appetite or energy intake (H. J. Smit et al. 750 2012). This may explain why the early studies from Burns' group found positive effects, whereas 751 later studies did not; as processing may have rendered the active ingredient in the test drinks 752 inactive. In reality, this study concludes there is no efficacy of Fabuless ${ }^{\mathrm{TM}}$ in improving satiety. 
753 Fractionated oat oil (LOO) has a smaller particle size than milk globules (100 nm vs $1000 \mathrm{~nm})$ and 754 may remain partially undigested when entering the ileum. It has been shown to result in increased 755 circulation of PYY, GLP-1, and CCK, but no changes in energy intake (Ohlsson et al. 2014). The 756 authors claim that the concentration of polar lipid in the oil investigated is considerably higher than 757 those in Fabuless ${ }^{\mathrm{TM}}$, and the resulting liposomes are stable enough to pass through the stomach 758 without structural changes. This may explain the larger effect seen in postprandial concentrations of 759 CCK, PYY, and GLP-1 with LOO compared to Fabuless ${ }^{\mathrm{TM}}$, but further study is required to confirm 760 this.

761 Peters et al. (2014) reported no effect of droplet size when administered in a meal-replacement 762 drink, and they discuss the potential for the background effect of the drink (which contained $10 \mathrm{~g}$ of 763 protein in the $606 \mathrm{~kJ}$ drink) which may have decreased sensitivity to the lipids added. This is in 764 spite of the fact that lipolysis was significantly higher in the smaller droplet $(0.1 \mu \mathrm{m})$ compared to 765 the larger droplet $(3 \mu \mathrm{m})$. Marciani et al. (2009) showed that acid-unstable emulsions were broken 766 down in the stomach before entering the small intestine, whereas acid stable emulsions were not and 767 led to slower gastric emptying and greater satiety scores. A more recent study also found no 768 increase in subjective satiety or a decrease of energy intake when comparing Fabuless ${ }^{\mathrm{TM}}$ soft lipid 769 emulsions or hard emulsions (dairy and palm oil, respectively) which were matched for particle size 770 (Chan et al. 2017). The aforementioned findings regarding site delivery and acid stability may 771 explain the lack of significant difference between the droplet sizes in the study by Peters and 772 colleagues. Hussein et al. (2015) added locust bean gum to lipids of $6 \mu \mathrm{m}$ or $0.4 \mu \mathrm{m}$ and found that 773 these were more stable than a control coarse lipid of $6 \mu \mathrm{m}$ with no locust bean gum. This stability 774 allowed for delivery of the lipids to the duodenum, and resulted in slower gastric emptying and 775 decreased food intake, without altering subjective sensations of appetite. This shows that the 776 development of novel foods containing small lipid droplets which remain unchanged in the stomach 777 until breakdown in the duodenum could be a promising avenue to increase satiety. 
Effects on satiety of chronic consumption of small particle lipids

780 To the authors' knowledge, only three studies to date have investigated SPL chronically, and these 781 investigated Fabuless ${ }^{\mathrm{TM}}$. Logan et al. (2006) found no significant suppressive effects of the novel 782 lipid emulsion on either satiety or food intake. There are some methodological limitations which 783 may have affected the results, such as the ad libitum trials being conducted in social environments 784 instead of a secluded booth. However, despite errors in design, this study does not support the 785 previous findings of Fabuless ${ }^{\mathrm{TM}}$ as a long term mediator of satiety. Diepvens et al. (2007) found that 786 hunger was significantly decreased, and weight re-gain was significant in the placebo group but not 787 in the emulsion group, indicating Fabuless ${ }^{\mathrm{TM}}$ may be useful in weight maintenance. However, Heer 788 (2012) discussed that the $1.2 \mathrm{~kg}$ difference in body mass between groups may not be clinically 789 significant or even attributed to the emulsion, as this can be achieved with a negative energy 790 balance of $100 \mathrm{kcal} \cdot$ day over the 18 week period. A more recent study investigated the concurrent 791 application of a low-calorie diet (1500 kcal-day), an exercise program, and supplementation of $4.2 \mathrm{~g}$ 792 of Olibra or $3.9 \mathrm{~g}$ milk fat for a 12 week period (Rebello et al. 2012). They concluded no significant 793 effect of supplementation with the emulsion on energy intake, subjective feelings of fullness or 794 body weight/composition. Thus, there appears to be little evidence that Fabuless ${ }^{\mathrm{TM}}$ can be useful in 795 promoting satiety and decreasing energy intake.

796 More studies are required, examining different small lipid droplet emulsions and satiety, to confirm 797 whether there is a long-term effect. It would be beneficial to develop a novel lipid or food product 798 such as capsules - which could release smaller lipid droplets directly into the ileum. Once this has 799 been developed and shown to decrease satiety when administered acutely, then chronic strategies to 800 enhance satiety can be examined. 


\section{Discussion and future directions}

802 There is some evidence to suggest that the lipids included in this review do provide satiating effects; 803 however, the side effects of taking these, particularly in high doses, must be taken into 804 consideration. The evidence presented here suggests that the lipids with the most potential to 805 enhance satiety are MCTs. SCFA can also promote satiety, but oral administration is more likely 806 linked to poor tolerability rather than a satiety effect. MCT have been shown to enhance satiety 807 when administered in beverage form (Rolls et al. 1988), when added to pasta (Van Wymelbeke et 808 al. 1998), and non-significant trends have been seen when incorporated into a fried breakfast 809 (Clegg, Golsorkhi, and Henry 2013). As aforementioned, MCT exert their appetite-suppressing 810 effects through an increase in ketone body production and not by an increase in appetite811 suppressing hormones. Therefore it is possible that combining MCT alongside other nutrients that 812 are potent stimulators of hormone release, such as protein (van der Klaauw et al. 2013) or indeed 813 other fats (Huda, Wilding, and Pinkney 2006; McLaughlin et al. 1999), would lead to an even 814 greater satiety response, although this is speculative.

815 Only one study to date has investigated CLA, and CLA led to reduced energy intake compared to a 816 control, but with no significant difference to MCT (Coleman, Quinn, and Clegg 2016). There was 817 no difference in self-reported hunger, fullness, desire to eat or prospective food consumption 818 between any of the three oils. Further studies should aim to analyse this further, in different modes 819 of delivery (i.e. liquid vs solid food).

820 SCFA do appear promising in the promotion of satiety, although this is difficult to quantify due to 821 the background effect of fibre utilised in many studies (Nilsson et al. 2013; Johansson et al. 2013; 822 Hlebowicz et al. 2008). Earlier studies investigating oral administration of SCFA initially seemed 823 promising, with reported increases in satiety (Ostman et al. 2005; Hlebowicz et al. 2008; Kondo et 824 al. 2009). A recent paper by Darzi and colleagues concluded that the apparent satiety effect is 
actually poor tolerability (Darzi et al. 2014). Whilst this indicates that oral administration of these

826 SCFA (acetate and propionate) is not recommended, no study to date has investigated oral 827 administration of butyrate. It is likely that the same result will be seen, and so studies investigating 828 this should consider nausea as a possible explanation for any apparent satiety effect.

829 DAG may influence satiety through a variety of mechanisms. The major limitation of DAG is its 830 availability. The product used in some of the studies mentioned in this review (Maki et al. 2002; 831 Yamamoto et al. 2001; Kamphuis, Mela, and Westerterp-Plantenga 2003) has since been withdrawn 832 from production, due to the presence of the carcinogenic glycidol fatty acid ester. DAG oil has been 833 verified as safe, with no adverse effects reported during 12 weeks of supplementation with a high 834 dosage of $0.5 \mathrm{~g} \cdot \mathrm{kg} \cdot \mathrm{d}$ (Yasunaga et al. 2004), although the DAG in this study was created by the 835 research group and not purchased commercially. Until a safe version of DAG is available which can 836 be purchased commercially, this does not appear to be a feasible avenue for the promotion of 837 satiety.

838 The evidence in support of fish oil and SPL is equivocal at best, with a majority of the research 839 indicating no benefit of SPL (Y. K. Chan et al. 2017; Peters et al. 2014), despite earlier studies 840 suggesting otherwise (Burns et al. 2001, 2000, 2002). In one study, fractionated oat oil was shown 841 to increase satiety and the circulating concentration of satiety hormones (Ohlsson et al. 2014), and 842 so more data is required to support these initial positive findings. $n$-3 PUFA can possibly be utilised 843 in increasing appetite in scenarios where this is necessary, such as in cancer patients (Jatoi et al. 844 2004; Zaid et al. 2012). There is a lack of studies investigating $n$-3 PUFA and satiety, and some of 845 the current evidence did not measure satiety or appetite specifically.

846 A recurring limitation of the use of functional lipids in the enhancement of satiety is the adverse 847 side effects commonly reported (Table 1). Both CLA and fish oil supplementation have been 848 reported to result in adverse side-effects in small doses of $6.8 \mathrm{~g} \cdot \mathrm{d}$ with CLA (Blankson et al. 2000) 
and $5 \mathrm{ml} \cdot \mathrm{d}$ with $n$-3 PUFA (Damsbo-Svendsen, Rønsholdt, and Lauritzen 2013). Intakes of $85 \mathrm{~g}$

850 have been reported with MCT (Jeukendrup et al. 1998). Where this high amount did result in GI

851 distress, it does show the potential for larger increases in satiety compared to some other lipids.

852 In conclusion, future work should examine the combination of these lipids with other 853 macronutrients (including fat) and other methods of promoting a negative energy balance in order to 854 assess the cumulative effects. As there is currently no study directly comparing the effects of these 855 lipids, it would be pertinent for this to be investigated. Finally, only one of the studies discussed in 856 this review has employed a design by which the participants swapped their daily oil for the test oil 857 (Kawashima et al. 2008). Considering that adding lipids to foods is counter-intuitive to an 858 individual attempting to decrease energy intake, this protocol should be examined in more studies 859 for ecological validity.

860

861 Acknowledgements

862 T.M. is supported by an Oxford Brookes University Nigel Groome Scholarship

863 T.M. and M.E.C. designed the manuscript. T.M. drafted the manuscript M.E.C. provided critical 864 revision of the manuscript. Both authors approved the final version of the manuscript.

865 Both authors declare no conflicts of interest.

870 References

871 Ackman, R.G. (2008). Fatty acids in fish and shellfish. In Fatty Acids in Foods and Their Health 872 Implications., edited by C.K. Chow, 3rded., 155-85. CRC PresS.

873 Agriculture, U.S.D. of. (2014). Nutrient intakes from food: mean amounts of consumed per 874 individual, by gender and age. What We Eat in America, National Health and Nutrition 875 Examination Survey, 2011-2012. 2014.

876 Aponte, G.W., A.S. Fink, J.H. Meyer, et al. (1985). Regional distribution and release of peptide yy 
with fatty acids of different chain length. American Journal of Physiology - Gastrointestinal and Liver Physiology. 249 (6):G745-50.

Armand, M. (2007). Lipases and lipolysis in the human digestive tract: where do we stand? Current Opinion in Clinical Nutrition and Metabolic Care. 10 (2):156-64.

Armand, M., B. Pasquier, M. André, et al. (1999). Digestion and absorption of 2 fat emulsions with different droplet sizes in the human digestive tract. The American Journal of Clinical Nutrition. 70 (6):1096-1106.

Arora, T., R.L. Loo, J. Anastasovska, et al. (2012). Differential effects of two fermentable carbohydrates on central appetite regulation and body composition. PLOS ONE. 7 (8):e43263.

Barber, M.D., J.A. Ross, and K.C.H. Fearon. (1998). The anti-cachectic effect of fatty acids. Proceedings of the Nutrition Society. 57:571-76.

Barber, M.D., J.A. Ross, A.C. Voss, et al. (1999). The effect of an oral nutritional supplement enriched with fish oil on weight-loss in patients with pancreatic cancer. British Journal of Cancer. 81 (1):80-86.

Barbera, R., M. Peracchi, F. Brighenti, et al. (2000). Sensations induced by medium and long chain triglycerides: role of gastric tone and hormones. Gut. 46 (1):32-36.

Batterham, R.L., M.A. Cowley, C.J. Small, et al. (2002). Gut hormone pyy3-36 physiologically inhibits food intake. Nature. 418 (6898). Nature Publishing Group:650-54.

Batterham, R.L., H. Heffron, S. Kapoor, et al. (2006). Critical role for peptide yy in proteinmediated satiation and body-weight regulation. Cell Metabolism. 4 (3):223-33.

Beglinger, S., J. Drewe, J. Schirra, et al. (2010). Role of fat hydrolysis in regulating glucagon-like peptide-1 secretion. Journal of Clinical Endocrinology and Metabolism. 95 (2):879-86.

Belury, M.A., A. Mahon, and S. Banni. (2003). Dairy product components and weight regulation the conjugated linoleic acid (cla) isomer, t10c12-cla, is inversely associated with changes in body weight and serum leptin in subjects with type 2 diabetes mellitus. Journal of Nutrition. 133:257-60.

Bender, N., M. Portmann, Z. Heg, et al. (2014). Fish or n3-pufa intake and body composition: a systematic review and meta-analysis. Obesity Reviews : An Official Journal of the International Association for the Study of Obesity. 15 (8):657-65.

Bergmann, J.F., O. Chassany, A. Petit, et al. (1992). Correlation between echographic gastric emptying and appetite: influence of psyllium. Gut. 33 (8):1042-43.

Bienenstock, J., W. Kunze, and P. Forsythe. (2015a). Microbiota and the gut-brain axis. Nutrition Reviews. 73 (suppl 1). 
Blankson, H., J.A. Stakkestad, H. Fagertun, et al. (2000). Conjugated linoleic acid reduces body fat mass in overweight and obese humans. Journal of Nutrition. 130 (12):2943-48.

Bloom, B., I.L. Chaikoff, and Reinhardt. (1951). Intestinal lymph as pathway for transport of absorbed fatty acids of different chain lengths. The American Journal of Physiology. 166 (2):451-55.

Blundell, J., C. De Graaf, T. Hulshof, et al. (2010). Appetite control: methodological aspects of the evaluation of foods. Obesity Reviews. 11 (3):251-70.

Blundell, J.E., V.J. Burley, J.R. Cotton, et al. (1993). Dietary fat and the control of energy intake:

Blundell, J.E., and J.I. MacDiarmid. (1997). Fat as a risk factor for overconsumption: satiation, satiety, and patterns of eating. Journal of the American Dietetic Association. 97 (7 Suppl):S639.

Blundell, J.E., P.J. Rogers, and A.J. Hill. (1987). Evaluating the satiating power of foods: implications for acceptance and consumption. In Food Acceptance and Nutrition., edited by J. Solms, D.A. Booth, R.M. Pangbourne, and O. Raunhardt, 205-19. London: Academic Press.

Borel, P., M. Armand, B. Pasquier, et al. (1994). Digestion and absorption of tube-feeding emulsions with different droplet sizes and compositions in the rat. Journal of Parenteral and Enteral Nutrition. 18 (6):534-43.

Borel, P., M. Armand, P. Ythier, et al. (1994). Hydrolysis of emulsions with different triglycerides and droplet sizes by gastric lipase in vitro. effect on pancreatic lipase activity. The Journal of Nutritional Biochemistry. 5 (3). Elsevier:124-33.

Borrelli, F., and A.A. Izzo. (2009). Role of acylethanolamides in the gastrointestinal tract with special reference to food intake and energy balance. Best Practice \& Research Clinical Endocrinology \& Metabolism. 23 (1):33-49.

Brown, A.J., E. Pang, and D.C. Roberts. (1991). Persistent changes in the fatty acid composition of erythrocyte membranes after moderate intake of n-3 polyunsaturated fatty acids: study design implications. The American Journal of Clinical Nutrition. 54 (4). American Society for Nutrition:668-73.

Brown, J.M., and M.K. McIntosh. (2003). Conjugated linoleic acid in humans: regulation of adiposity and insulin sensitivity. Journal of Nutrition. 133 (10):3041-46.

Bruera, E., F. Strasser, J.L. Palmer, et al. (2003). Effect of fish oil on appetite and other symptoms in patients with advanced cancer and anorexia/cachexia: a double-blind, placebo-controlled study. J Clin Oncol. 21:129-34. 
Bruggencate, S.J.M. Ten, I.M.J. Bovee-Oudenhoven, M.L.G. Lettink-Wissink, et al. (2005). Dietary fructooligosaccharides increase intestinal permeability in rats. The Journal of Nutrition. 135 (4):837-42.

Burns, A.A., M.B. Livingstone, R.W. Welch, et al. (2000). Short-term effects of yoghurt containing a novel fat emulsion on energy and macronutrient intakes in non-obese subjects. International Journal of Obesity and Related Metabolic Disorders : Journal of the International Association for the Study of Obesity. 24 (11):1419-25.

Burns, A.A., M.B.E. Livingstone, R.W. Welch, et al. (2001). The effects of yoghurt containing a novel fat emulsion on energy and macronutrient intakes in non-overweight, overweight and obese subjects. International Journal of Obesity. 25 (10). Nature Publishing Group:1487-96.

Burns, A.A., M.B.E. Livingstone, R.W. Welch, et al. (2002). Dose-response effects of a novel fat emulsion (olibra) on energy and macronutrient intakes up to $36 \mathrm{~h}$ post-consumption. Eur J Clin Nutr. 56 (4):368-77.

Byrne, C.S., E.S. Chambers, D.J. Morrison, et al. (2015). The role of short chain fatty acids in appetite regulation and energy homeostasis. International Journal of Obesity. 39 (9):1331-38.

Calder, P.C. (2010). Omega-3 fatty acids and inflammatory processes. Nutrients. 2:355-74.

Campbell, B., and R.B. Kreider. (2008). Conjugated linoleic acids. Current Sports Medicine Reports. 7 (4):237-41.

Campfield, L.A., F.J. Smith, M. Rosenbaum, et al. (1996). Human eating: evidence for a physiological basis using a modified paradigm. Neuroscience \& Biobehavioral Reviews. 20 (1):133-37.

Cani, P.D., E. Joly, Y. Horsmans, et al. (2006). Oligofructose promotes satiety in healthy human: a pilot study. European Journal of Clinical Nutrition. 60 (5):567-72.

Cao, Z.-P., F. Wang, X.-S. Xiang, et al. (2007). Intracerebroventricular administration of conjugated linoleic acid (cla) inhibits food intake by decreasing gene expression of npy and agrp. Neuroscience Letters. 418 (3):217-21.

Cawthorn, W.P., and J.K. Sethi. (2008). Tnf-alpha and adipocyte biology. FEBS Letters. 582 (1):117-31.

Chalon, S. (2006). Omega-3 fatty acids and monoamine neurotransmission. Prostaglandins, Leukotrienes, and Essential Fatty Acids. 75 (4-5):259-69.

Chambers, E.S., A. Viardot, A. Psichas, et al. (2015). Effects of targeted delivery of propionate to the human colon on appetite regulation, body weight maintenance and adiposity in overweight adults. Gut. 64 (11):1744-54.

Chambers, L., K. McCrickerd, and M.R. Yeomans. (2015). Optimising foods for satiety. Trends in 

Food Science \& Technology. 41 (2):149-60.

Chan, Y.-K., C.M. Strik, S.C. Budgett, et al. (2012). The emulsified lipid fabuless (olibra) does not decrease food intake but suppresses appetite when consumed with yoghurt but not alone or with solid foods: a food effect study. Physiology \& Behavior. 105 (3):742-48.

Chan, Y.K., S.C. Budgett, A.K. MacGibbon, et al. (2017). Small particle size lipid emulsions, satiety and energy intake in lean men. Physiology \& Behavior. 169:98-105.

Choi, Y., Y.-C. Kim, Y.-B. Han, et al. (2000). Nutrient-gene expression the trans-10,cis-12 isomer of conjugated linoleic acid downregulates stearoyl-coa desaturase 1 gene expression in 3t3-11 adipocytes 1. Journal of Nutrition. 130:1920-24.

Chowdhury, R., S. Stevens, D. Gorman, et al. (2012). Association between fish consumption, long chain omega 3 fatty acids, and risk of cerebrovascular disease: systematic review and metaanalysis. BMJ. 345.

Clark, M.J., and J.L. Slavin. (2013). The effect of fiber on satiety and food intake: a systematic review. Journal of the American College of Nutrition. 32 (3):200-211.

Clegg, M., and A. Shafat. (2009). The role of fat in gastric emptying and satiety: acute and chronic effects. The Proceedings of the Nutrition Society. 68 (1):89-97.

Clegg, M.E. (2010). Medium-chain triglycerides are advantageous in promoting weight loss although not beneficial to exercise performance. International Journal of Food Sciences and Nutrition. 61 (7):653-79.

Clegg, M.E., M. Golsorkhi, and C.J. Henry. (2013). Combined medium-chain triglyceride and chilli feeding increases diet-induced thermogenesis in normal-weight humans. European Journal of Nutrition. 52 (6):1579-85.

Cohn, J.S., J.R. Mcnamara, S.D. Cohn, et al. (1988). Postprandial plasma lipoprotein changes in human subjects of different ages. Journal of Lipid Research. 29:469-79.

Coleman, H., P. Quinn, and M.E. Clegg. (2016). Medium chain triglycerides and conjugated linoleic acids in beverage form increase satiety and reduce food intake in humans. Nutrition Research.

Cone, R.D. (2005). Anatomy and regulation of the central melanocortin system. Nature Neuroscience. 8 (5):571-78.

Cordeira, J.W., L. Frank, M. Sena-Esteves, et al. (2010). Brain-derived neurotrophic factor regulates hedonic feeding by acting on the mesolimbic dopamine system. Journal of Neuroscience. 30 (7).

Cornish, S.M., D.G. Candow, N.T. Jantz, et al. (2009). Conjugated linoleic acid combined with creatine monohydrate and whey protein supplementation during strength training. 
D’Alonzo, R.P., W.J. Kozarek, and R.L. Wade. (1982). Glyceride composition of processed fats and oils as determined by glass capillary gas chromatography. Journal of the American Oil Chemists'Society. 59 (7). Springer-Verlag:292-95.

Dagher, A. (2009). The neurobiology of appetite: hunger as addiction. International Journal of Obesity. 33 (June). Nature Publishing Group:S30-33.

Dailey, M.J., and T.H. Moran. (2013). Glucagon-like peptide 1 and appetite. Trends in Endocrinology and Metabolism. 24 (2):85-91.

Damsbo-Svendsen, S., M.D. Rønsholdt, and L. Lauritzen. (2013). Fish oil-supplementation increases appetite in healthy adults. a randomized controlled cross-over trial. Appetite. 66 (July):62-66.

Darwiche, G., E. Östman, H. Elmståhl, et al. (2001). Measurements of the gastric emptying rate by 1025 use of ultrasonography: studies in humans using bread with added sodium propionate. American Journal of Clinical Nutrition. 74 (2). American Society for Clinical Nutrition:254-

Darzi, J., G.S. Frost, R. Montaser, et al. (2014). Influence of the tolerability of vinegar as an oral 1029 source of short-chain fatty acids on appetite control and food intake. International Journal of Obesity. 38 (5). Nature Publishing Group:675-81.

Darzi, J., G.S. Frost, and M.D. Robertson. (2011). Do scfa have a role in appetite regulation? Proceedings of the Nutrition Society. 70 (1):119-28.

Darzi, J., G.S. Frost, and M.D. Robertson. (2012). Effects of a novel propionate-rich sourdough bread on appetite and food intake. European Journal of Clinical Nutrition. 66 (7):789-94.

Das, S.K., C.H. Gilhooly, J.K. Golden, et al. (2007). Long-term effects of 2 energy-restricted diets differing in glycemic load on dietary adherence, body composition, and metabolism in calerie: a 1-y randomized controlled trial. The American Journal of Clinical Nutrition. 85 (4):1023-30. Daud, N.M., N.A. Ismail, E.L. Thomas, et al. (2014). The impact of oligofructose on stimulation of gut hormones, appetite regulation and adiposity. Obesity. 22 (6):1430-38.

Deforche, B., D. Van Dyck, T. Deliens, et al. (2015). Changes in weight, physical activity, sedentary behaviour and dietary intake during the transition to higher education: a prospective study. The International Journal of Behavioral Nutrition and Physical Activity. 12 (February). BioMed Central:16.

Delaere, F., A. Duchampt, L. Mounien, et al. (2013). The role of sodium-coupled glucose cotransporter 3 in the satiety effect of portal glucose sensing. Molecular Metabolism. Vol. 2. DeLany, J.P., F. Blohm, a a Truett, et al. (1999). Conjugated linoleic acid rapidly reduces body fat 
content in mice without affecting energy intake. The American Journal of Physiology. 276:R1172-79.

Denroche, H.C., F.K. Huynh, and T.J. Kieffer. (2012). The role of leptin in glucose homeostasis. Journal of Diabetes Investigation. 3 (2). Wiley-Blackwell:115-29.

Department of Health. (1984). Diet and cardiovascular disease. committee on medical aspects of 1052 food policy. report of the panel on diet in relation to cardiovascular disease. Reports on Health and Social Subjects. 28:1-32.

Diepvens, K., S. Soenen, J. Steijns, et al. (2007). Long-term effects of consumption of a novel fat 1055 1056 emulsion in relation to body-weight management. International Journal of Obesity. 31:94249.

Dodson, S., V.E. Baracos, A. Jatoi, et al. (2011). Muscle wasting in cancer cachexia: clinical implications, diagnosis, and emerging treatment strategies. Annual Review of Medicine. 62 (1):265-79.

Dong, L., G. Block, and S. Mandel. (2004). Activities contributing to total energy expenditure in the united states: results from the nhaps study. International Journal of Behavioral Nutrition and Physical Activity. 1 (1):4.

Donohoe, C.L., A.M. Ryan, and J. V Reynolds. (2011). Cancer cachexia: mechanisms and clinical implications. Gastroenterology Research and Practice. 2011. Hindawi Publishing Corporation:601434.

Dreon, D.M., B. Frey-Hewitt, N. Ellsworth, et al. (1988). Dietary fat:carbohydrate ratio and obesity in middle-aged men. The American Journal of Clinical Nutrition. 47 (6):995-1000.

Drewe, J., A. Gadient, L.C. Rovati, et al. (1992). Role of circulating cholecystokinin in control of fat-induced inhibition of food intake in humans. Gastroenterology. 102 (5):1654-59.

Drewnowski, A., and N. Darmon. (2005). The economics of obesity: dietary energy density and energy cost. The American Journal of Clinical Nutrition. 82 (1 Suppl):265S-273S.

Ebrahimi, M., M. Ghayour-Mobarhan, S. Rezaiean, et al. (2009). Omega-3 fatty acid supplements improve the cardiovascular risk profile of subjects with metabolic syndrome, including markers of inflammation and auto-immunity. Acta Cardiologica. 64 (3):321-27.

Ello-Martin, J.A., J.H. Ledikwe, and B.J. Rolls. (2005). The influence of food portion size and energy density on energy intake: implications for weight management. The American Journal of Clinical Nutrition. 82 (1 Suppl):236S-241S.

Evans, K., P.J. Kuusela, M.L. Cruz, et al. (1988). Rapid chylomicron appearance following sequential meals: effects of second meal composition. British Journal of Nutrition. 79:425-29.

Favé, G., T.C. Coste, and M. Armand. (2004). Physicochemical properties of lipids: new strategies 
to manage fatty acid bioavailability. Cellular and Molecular Biology. 50 (7):815-31.

Feinle, C., D. O’Donovan, S. Doran, et al. (2003). Effects of fat digestion on appetite, apd motility, and gut hormones in response to duodenal fat infusion in humans. American Journal of Physiology - Gastrointestinal and Liver Physiology. 284 (5).

Feinle, C., T. Rades, B. Otto, et al. (2001). Fat digestion modulates gastrointestinal sensations induced by gastric distention and duodenal lipid in humans. Gastroenterology. 120 (5):11001107.

Feltrin, K.L., T.J. Little, J.H. Meyer, et al. (2004). Effects of intraduodenal fatty acids on appetite, antropyloroduodenal motility, and plasma cck and glp-1 in humans vary with their chain length. American Journal of Physiology. Regulatory, Integrative and Comparative Physiology. 287:R524-33.

Feltrin, K.L., T.J. Little, J.H. Meyer, et al. (2007). Effects of lauric acid on upper gut motility, plasma cholecystokinin and peptide yy, and energy intake are load, but not concentration, dependent in humans. The Journal of Physiology. 581 (2):767-77.

Feltrin, K.L., M. Patterson, M.A. Ghatei, et al. (2006). Effect of fatty acid chain length on suppression of ghrelin and stimulation of pyy, glp-2 and pp secretion in healthy men. Peptides. 27 (7):1638-43.

Fielding, B.A., J. Callow, R.M. Owen, et al. (1996). Postprandial lipemia: the origin of an early peak studied by specific dietary fatty acid intake during sequential meals. The American Journal of Clinical Nutrition. 63 (1):36-41.

Flickinger, B.D., and N. Matsuo. (2003). Nutritional characteristics of dag oil. Lipids. 38 (2):129_ 32.

Flint, A., A. Raben, A. Astrup, et al. (1998). Glucagon-like peptide 1 promotes satiety and suppresses energy intake in humans. Journal of Clinical Investigations. 101 (3):515-20.

Franklin, J.C., B.C. Schiele, J. Brozek, et al. (1948). Observations on human behavior in experimental semi-starvation and rehabilitation. Journal of Clinical Psychology. 4 (1):28-45.

Freeland, K.R., C. Wilson, and T.M. Wolever. (2010). Adaptation of colonic fermentation and glucagon-like peptide-1 secretion with increased wheat fibre intake for 1 year in hyperinsulinaemic human subjects. British Journal of Nutrition. 103 (1):82-90.

French, S.J., C.A. Conlon, S.T. Mutuma, et al. (2000). The effects of intestinal infusion of longchain fatty acids on food intake in humans. Gastroenterology. 119 (4):943-48.

Friedman, J.M., and J.L. Halaas. (1998). Leptin and the regulation of body weight in mammals. Nature. 395 (6704). Nature Publishing Group:763-70.

Friedman, M.I., R.B. Harris, H. Ji, et al. (1999). Fatty acid oxidation affects food intake by altering 
hepatic energy status. The American Journal of Physiology. 276 (4 Pt 2):R1046-53.

1116

Frost, G., M.L. Sleeth, M. Sahuri-Arisoylu, et al. (2014). The short-chain fatty acid acetate reduces appetite via a central homeostatic mechanism. Nature Communications. 5.

Fu J., Gaetani S., Oveisi F., et al. (2003). Oleylethanolamide regulates feeding and body weight through activation of the nuclear receptor ppar-alpha. Nature. 425 (6953).

Fujimoto, T., and R.G. Parton. (2011). Not just fat: the structure and function of the lipid droplet. Cold Springs Harbor Perspectives in Biology. 3 (3).

Gaullier, J.-M., J. Halse, H.O. Høivik, et al. (2007). Six months supplementation with conjugated linoleic acid induces regional-specific fat mass decreases in overweight and obese. British Journal of Nutrition. 97:550-60.

Gaullier, J.-M., J. Halse, K. Høye, et al. (2005). Supplementation with conjugated linoleic acid for 24 months is well tolerated by and reduces body fat mass in healthy, overweight humans. The Journal of Nutrition. 135 (4):778-84.

Geliebter, A. (1988). Gastric distension and gastric capacity in relation to food intake in humans. Physiology \& Behavior. 44 (4):665-68.

Gibbs, J., R.C. Young, and G.P. Smith. (1973). Cholecystokinin elicits satiety in rats with open gastric fistulas. Nature, UK. 245 (5424):323-25.

Gibney, M.J., and T.M. Wolever. (1997). Periodicity of eating and human health: present perspective and future directions. The British Journal of Nutrition. 77 Suppl 1 (April):S3-5.

Goedecke, J.H., V.R. Clark, T.D. Noakes, et al. (2005). The effects of medium-chain triacylglycerol and carbohydrate ingestion on ultra-endurance exercise performance. International Journal of Sport Nutrition and Exercise Metabolism. 15 (1):15-27.

Graaf, C. De, W.A.M. Blom, P.A.M. Smeets, et al. (2004). Biomarkers of satiation and satiety. American Journal of Clinical Nutrition.

Green, S.M., J.K. Wales, C.L. Lawton, et al. (2000). Comparison of high-fat and high-carbohydrate foods in a meal or snack on short-term fat and energy intakes in obese women*. British Journal of Nutrition. 84:521-30.

Guh, D.P., W. Zhang, N. Bansback, et al. (2009). The incidence of co-morbidities related to obesity and overweight: a systematic review and meta-analysis. BMC Public Health. 9:88.

Hansen, R.A., G.K. Ogilvie, D.J. Davenport, et al. (1998). Duration of effects of dietary fish oil supplementation on serum eicosapentaenoic acid and docosahexaenoic acid concentrations in dogs. American Journal of Veterinary Research. 59 (7):864-68.

Hargrave, K.M., C. Li, B.J. Meyer, et al. (2002). Adipose depletion and apoptosis induced by trans10, cis-12 conjugated linoleic acid in mice. Obesity Research. 10 (12):1284-90. 
1149

1150

Heer, M. (2012). An analysis of the \&quot; effect of olibra: a 12-week randomized control trial and a review of earlier studies \&quot; Journal of Diabetes Science and Technology J Diabetes Sci Technol. 66 (33):709-11.

Hetherington, M.M., K. Cunningham, L. Dye, et al. (2013). Potential benefits of satiety to the consumer: scientific considerations. Nutrition Research Reviews. 26:22-38.

Heymsfield, S.B., J.B. Harp, M.L. Reitman, et al. (2007). Why do obese patients not lose more weight when treated with low-calorie diets? a mechanistic perspective. The American Journal of Clinical Nutrition. 85 (2):346-54.

Hildebrand, P., C. Beglinger, K. Gyr, et al. (1990). Effects of a cholecystokinin receptor antagonist on intestinal phase of pancreatic and biliary responses in man. The Journal of Clinical Investigation. 85:640-46.

Hlebowicz, J., S. Lindstedt, O. Björgell, et al. (2008). Botanical integrity of wheat products influences the gastric distention and satiety in healthy subjects. Nutrition Journal. BioMed Central.

Huda, M.S.B., J.P.H. Wilding, and J.H. Pinkney. (2006). Gut peptides and the regulation of appetite. Obesity Reviews. 7 (2):163-82.

Hunt, J.N., and M.T. Knox. (1968). A relation between the chain length of fatty acids and the slowing of gastric emptying. The Journal of Physiology. 194 (2):327-36.

Hussein, M.O., C.L. Hoad, J. Wright, et al. (2015). Fat emulsion intragastric stability and droplet size modulate gastrointestinal responses and subsequent food intake in young adults. Journal of Nutrition. 145 (6):1170-77.

Iwata, T., T. Kamegai, Y. Yamauchi-Sato, et al. (2007). Safety of dietary conjugated linoleic acid (cla) in a 12-weeks trial in healthy overweight japanese male volunteers. Journal of Oleo Science. 56 (10):517-25.

Jatoi, A., K. Rowland, C.L. Loprinzi, et al. (2004). An eicosapentaenoic acid supplement versus megestrol acetate versus both for patients with cancer-associated wasting: a north central cancer treatment group and national cancer institute of canada collaborative effort. Journal of Clinical Oncology. 22 (12):2469-76.

Jeukendrup, A.E., J.J. Thielen, A.J. Wagenmakers, et al. (1998). Effect of medium-chain triacylglycerol and carbohydrate ingestion during exercise on substrate utilization and subsequent cycling performance. The American Journal of Clinical Nutrition. 67 (3):397-404.

Jiménez-Gómez, Y., C. Marín, P. Peérez-Martínez, et al. (2010). A low-fat, high-complex carbohydrate diet supplemented with long-chain (n-3) fatty acids alters the postprandial lipoprotein profile in patients with metabolic syndrome. The Journal of Nutrition. 140 
(9):1595-1601.

Johansson, E. V, A.C. Nilsson, E.M. Östman, et al. (2013). Effects of indigestible carbohydrates in barley on glucose metabolism, appetite and voluntary food intake over $16 \mathrm{~h}$ in healthy adults. Nutrition Journal. 12 (1):46.

Jouët, P., D. Moussata, H. Duboc, et al. (2013). Effect of short-chain fatty acids and acidification on the phasic and tonic motor activity of the human colon. Neurogastroenterology \& Motility. 25 (12):943-49.

Kahler, A., M. Zimmermann, and W. Langhans. (1999). Suppression of hepatic fatty acid oxidation and food intake in men. Nutrition. 15 (11):819-28.

Kaji, I., S. Karaki, R. Tanaka, et al. (2011). Density distribution of free fatty acid receptor 2 (ffa2)expressing and glp-1-producing enteroendocrine 1 cells in human and rat lower intestine, and increased cell numbers after ingestion of fructo-oligosaccharide. Journal of Molecular Histology. 42 (1):27-38.

Kamphuis, M., M. Lejeune, W.H.M. Saris, et al. (2003). Effect of conjugated linoleic acid supplementation after weight loss on appetite and food intake in overweight subjects. European Journal of Clinical Nutrition 57 (10):1268-74.

Kamphuis, M., D. Mela, and M. Westerterp-Plantenga. (2003). Diacylglycerols affect substrate oxidation and appetite in humans 1-3. American Journal of Clinical Nutrition. 77 (5):1133-1139.

Kawashima, H., H. Takase, K. Yasunaga, et al. (2008). One-year ad libitum consumption of diacylglycerol oil as part of a regular diet results in modest weight loss in comparison with consumption of a triacylglycerol control oil in overweight japanese subjects. Journal of the American Dietetic Association. 108 (1):57-66.

Kennedy, A., K. Martinez, S. Schmidt, et al. (2010). Antiobesity mechanisms of action of conjugated linoleic acid. The Journal of Nutritional Biochemistry. 21 (3):171-79.

Klaauw, A.A. van der, J.M. Keogh, E. Henning, et al. (2013). High protein intake stimulates postprandial glp1 and pyy release. Obesity. 21 (8):1602-7.

Klok, M.D., S. Jakobsdottir, and M.L. Drent. (2007). The role of leptin and ghrelin in the regulation of food intake and body weight in humans: a review. Obesity Reviews. 8 (1):21-34.

Knutson, L., D.J. Koenders, H. Fridblom, et al. (2010). Gastrointestinal metabolism of a vegetableoil emulsion in healthy subjects 1-3. Am J Clin Nutr. 92:515-24.

Kondo, T., M. Kishi, T. Fushimi, et al. (2009). Vinegar intake reduces body weight, body fat mass, and serum triglyceride levels in obese japanese subjects. Bioscience, Biotechnology, and Biochemistry. 73 (8):1837-43. 
Kreider, R.B., C.D. Wilborn, L. Taylor, et al. (2010). Issn exercise sport nutrition review: research recommendations. Journal of the International Society If Sports Nutrition. 7 (7).

Krotkiewski, M. (2001). Value of vlcd supplementation with medium chain triglycerides. International Journal of Obesity and Related Metabolic Disorders. 25 (9):1393-1400.

Kuwahara, A. (2014). Contributions of colonic short-chain fatty acid receptors in energy homeostasis. Frontiers in Endocrinology. 5 (September). Frontiers:144.

Laeger, T., C.C. Metges, and B. Kuhla. (2010). Role of $\beta$-hydroxybutyric acid in the central regulation of energy balance. Appetite.

Lal, S., J. McLaughlin, J. Barlow, et al. (2004). Cholecystokinin pathways modulate sensations induced by gastric distension in humans. American Journal of Physiology. Gastrointestinal and Liver Physiology. 287:G72-79.

Lambert, D.M., and G.G. Muccioli. (2007). Endocannabinoids and related n-acylethanolamines in the control of appetite and energy metabolism: emergence of new molecular players. Current Opinion in Clinical Nutrition and Metabolic Health. 10 (6):735-44.

Lambert, E. V, J.H. Goedecke, K. Bluett, et al. (2007). Conjugated linoleic acid versus high-oleic acid sunflower oil: effects on energy metabolism, glucose tolerance, blood lipids, appetite and body composition in regularly exercising individuals. British Journal of Nutrition. 97 (5):1001-11.

Langhans, W., C. Leitner, M. Arnold, et al. (2011). Dietary fat sensing via fatty acid oxidation in enterocytes: possible role in the control of eating. American Journal of Physiology. Regulatory, Integrative and Comparative Physiology. 300 (3). American Physiological Society:R554-65.

Langhans, W., and E. Scharrer. (1987). Evidence for a vagally mediated satiety signal derived from hepatic fatty acid oxidation. Journal of the Autonomic Nervous System. 18 (1). Elsevier:13-18.

Ledeboer, M., A.A. Masclee, I. Biemond, et al. (1999). Differences in cholecystokinin release and gallbladder contraction between emulsified and nonemulsified long-chain triglycerides. Journal of Parenteral and Enteral Nutrition. 23 (4):203-6.

Leonhardt, M., and W. Langhans. (2004). Fatty acid oxidation and control of food intake. Physiology \& Behavior. 83 (4):645-51.

Li, D., T. Xu, H. Takase, et al. (2008). Diacylglycerol-induced improvement of whole-body insulin sensitivity in type 2 diabetes mellitus: a long-term randomized, double-blind controlled study. Clinical Nutrition. 27 (2):203-11.

Liddle, R.A., E.T. Morita, C.K. Conrad, et al. (1986). Regulation of gastric emptying in humans by cholecystokinin. The Journal of Clinical Investigation. 77 (3). American Society for Clinical 
Investigation:992-96.

Liljeberg, H.G., and I.M. Björck. (1996). Delayed gastric emptying rate as a potential mechanism for lowered glycemia after eating sourdough bread: studies in humans and rats using test products with added organic acids or an organic salt. The American Journal of Clinical Nutrition. 64 (6):886-93.

Logan, C., T. Mccaffrey, J. Wallace, et al. (2006). Investigation of the medium-term effects of olibra fat emulsion on food intake in non-obese subjects. European Journal of Clinical Nutrition. 60:1081-91.

Lorente-Cebrián, S., A.G. V Costa, S. Navas-Carretero, et al. (2013). Role of omega-3 fatty acids in obesity, metabolic syndrome, and cardiovascular diseases: a review of the evidence. Journal of Physiology and Biochemistry. 69 (3):633-51.

Maas, M.I.M., W.P.M. Hopman, M.B. Katan, et al. (1998). Release of peptide yy and inhibition of gastric acid secretion by long-chain and medium-chain triglycerides but not by sucrose polyester in men. European Journal of Clinical Investigation. 28 (2):123-30.

Maki, K.C., M.H. Davidson, R. Tsushima, et al. (2002). Consumption of diacylglycerol oil as part of a reduced-energy diet enhances loss of body weight and fat in comparison with consumption of a triacylglycerol control oil 1-3. American Journal of Clinical Nutrition. 76:1230-36.

Maljaars, P.W.J., H.P.F. Peters, A. Kodde, et al. (2011). Length and site of the small intestine exposed to fat influences hunger and food intake. British Journal of Nutrition. 106 (10):160915.

Maljaars, P.W.J., R.J.P. Van Der Wal, T. Wiersma, et al. (2012). The effect of lipid droplet size on satiety and peptide secretion is intestinal site-specific. Clinical Nutrition. 31:535-42.

Marciani, L., R. Faulks, M.S.J. Wickham, et al. (2009). Effect of intragastric acid stability of fat emulsions on gastric emptying, plasma lipid profile and postprandial satiety. British Journal of Nutrition. 101 (6):919-28.

Marten, B., M. Pfeuffer, and J. Schrezenmeir. (2006). Medium-chain triglycerides. International Dairy Journal.

Matzinger, D., L. Degen, J. Drewe, et al. (2000). The role of long chain fatty acids in regulating food intake and cholecystokinin release in humans. Gut. 46 (5):688-93.

Matzinger, D., J.-P. Gutzwiller, J. Drewe, et al. (1999). Inhibition of food intake in response to intestinal lipid is mediated by cholecystokinin in humans. The American Journal of Physiology. 277 (6 Pt 2):R1718-24.

Mayer, J. (1953). Glucostatic mechanism of regulation of food intake. The New England Journal of Medicine. 249 (1):13-16. 
McLaughlin, J., M. Grazia Lucà, M.N. Jones, et al. (1999). Fatty acid chain length determines cholecystokinin secretion and effect on human gastric motility. Gastroenterology. 116 (1):4653.

McLaughlin, J.T., R.B. Lomax, L. Hall, et al. (1998). Fatty acids stimulate cholecystokinin secretion via an acyl chain length-specific, $\mathrm{ca}^{2+}$-dependent mechanism in the enteroendocrine cell line stc-1. The Journal of Physiology. 513 (1):11-18.

Medina, E.A., W.F. Horn, N.L. Keim, et al. (2000). Conjugated linoleic acid supplementation in humans: effects on circulating leptin concentrations and appetite. Lipids. 35 (7):783-88.

Mettler, S., I. Schwarz, and P.C. Colombani. (2009). Additive postprandial blood glucoseattenuating and satiety-enhancing effect of cinnamon and acetic acid. Nutrition Research. 29 (10):723-27.

Millington, G.W.M. (2007). The role of proopiomelanocortin (pomc) neurones in feeding behaviour. Nutrition \& Metabolism. 4 (1):18.

Miner, J.L., C.A. Cederberg, M.K. Nielsen, et al. (2001). Conjugated linoleic acid (cla), body fat, and apoptosis. Obesity Research. 9 (2):129-34.

Morton, G., and M. Schwartz. (2006). Central nervous system control of food intake and body weight. Nature Reviews. 443 (7109):289-95.

Mushtaq, S., E. Heather Mangiapane, and K.A. Hunter. (2010). Estimation of cis-9, trans-11 conjugated linoleic acid content in uk foods and assessment of dietary intake in a cohort of healthy adults. The British Journal of Nutrition. 103 (9):1366-74.

Myers, M.G., M.A. Cowley, and H. Unzberg. (2008). Mechanisms of leptin action and leptin resistance. Annu. Rev. Physiol. 70:537-56.

Nagao, T., H. Watanabe, N. Goto, et al. (2000). Dietary diacylglycerol suppresses accumulation of body fat compared to triacylglycerol in men in a double-blind controlled trial. Journal of Nutrition. 130:792-97.

Nilsson, A., E. Johansson, L. Ekstrom, et al. (2013). Effects of a brown beans evening meal on metabolic risk markers and appetite regulating hormones at a subsequent standardized breakfast: a randomized cross-over study. PLoS One. 8 (4):e59985.

Norris, L.E., A.L. Collene, M.L. Asp, et al. (2009). Comparison of dietary conjugated linoleic acid with safflower oil on body composition in obese postmenopausal women with type 2 diabetes mellitus. American Journal of Clinical Nutrition. 90 (3):468-76.

Ohlsson, L., A. Rosenquist, J.F. Rehfeld, et al. (2014). Postprandial effects on plasma lipids and satiety hormones from intake of liposomes made from fractionated oat oil: two randomized crossover studies. Food and Nutrition Research. 58 (9):1-11. 
Onakpoya, I.J., P.P. Posadzki, L.K. Watson, et al. (2012). The efficacy of long-term conjugated linoleic acid (cla) supplementation on body composition in overweight and obese individuals: a systematic review and meta-analysis of randomized clinical trials. European Journal of Nutrition.

Ostman, E., Y. Granfeldt, L. Persson, et al. (2005). Vinegar supplementation lowers glucose and insulin responses and increases satiety after a bread meal in healthy subjects. European Journal of Clinical Nutrition. 59 (9):983-88.

Page, K.A., A. Williamson, N. Yu, et al. (2009). Medium-chain fatty acids improve cognitive function in intensively treated type 1 diabetic patients and support in vitro synaptic transmission during acute hypoglycemia. Diabetes. 58:1237-44.

Pagotto, U., G. Marsicano, D. Cota, et al. (2006). The emerging role of the endocannabinoid system in endocrine regulation and energy balance. Endocrine Reviews. 27 (1):73-100.

Paniagua, J.A., P. Pérez-Martinez, I.M.F. Gjelstad, et al. (2011). A low-fat high-carbohydrate diet supplemented with long-chain n-3 pufa reduces the risk of the metabolic syndrome. Atherosclerosis. 218 (2):443-50.

Pariza, M.W., Y. Park, and M.E. Cook. (2001). The biologically active isomers of conjugated linoleic acid. Progress in Lipid Research. 40 (4):283-98.

Park, Y., K.J. Albright, W. Liu, et al. (1997). Effect of conjugated linoleic acid on body composition in mice. Lipids. 32:853-58.

Park, Y., K.J. Albright, J.M. Storkson, et al. (2007). Conjugated linoleic acid (cla) prevents body fat accumulation and weight gain in an animal model. Journal of Food Science. 72 (8):S612-17.

Park, Y., J.M. Storkson, K.J. Albright, et al. (1999). Evidence that the trans-10,cis-12 isomer of conjugated linoleic acid induces body composition changes in mice. Lipids. 34 (3):235-41.

Parnell, J.A., and R.A. Reimer. (2009). Weight loss during oligofructose supplementation is associated with decreased ghrelin and increased peptide yy in overweight and obese adults. American Journal of Clinical Nutrition. 89 (6):1751-59.

Parra, D., A. Ramel, N. Bandarra, et al. (2008). A diet rich in long chain omega-3 fatty acids modulates satiety in overweight and obese volunteers during weight loss. Appetite. 51 (3):67680.

Paz-Filho, G.J. da, A. Volaco, H.L. Suplicy, et al. (2009). Decrease in leptin production by the adipose tissue in obesity associated with severe metabolic syndrome. Arquivos Brasileiros de Endocrinologia E Metabologia. 53 (9):1088-95.

Perry, B., and Y. Wang. (2012). Appetite regulation and weight control: the role of gut hormones. Nutrition and Diabetes. 2 (e26). 
Peters, H.P.F., E.C.M. Bouwens, E.A.H. Schuring, et al. (2014). The effect of submicron fat droplets in a drink on satiety, food intake, and cholecystokinin in healthy volunteers. European Journal of Nutrition. 53 (3). Springer Berlin Heidelberg:723-29.

Petersen, G., C. Sørensen, P.C. Schmid, et al. (2006). Intestinal levels of anandamide and oleoylethanolamide in food-deprived rats are regulated through their precursors. Biochimica et Biophysica Acta. 1761 (2):143-50.

Pilichiewicz, A., D. O’Donovan, C. Feinle, et al. (2003). Effect of lipase inhibition on gastric emptying of, and the glycemic and incretin responses to, an oil/aqueous drink in type 2 diabetes mellitus. The Journal of Clinical Endocrinology \& Metabolism. 88 (8):3829-34.

Pinkoski, C., P.D. Chilibeck, D.G. Candow, et al. (2006). The effects of conjugated linoleic acid supplementation during resistance training. Medicine and Science in Sports and Exercise. 38 (2):339-48.

Pironi, L., V. Stanghellini, M. Miglioli, et al. (1993). Fat-induced ileal brake in humans: a dosedependent phenomenon correlated to the plasma levels of peptide yy. Gastroenterology. 105 (3):733-39.

Poppitt, S.D., C.M. Strik, A.K.H. MacGibbon, et al. (2010). Fatty acid chain length, postprandial satiety and food intake in lean men. Physiology and Behaviour. 101 (1):161-67.

Psichas, A., M. Sleeth, K. Murphy, et al. (2014). The short chain fatty acid propionate stimulates glp-1 and pyy secretion via free fatty acid receptor 2 in rodents. International Journal of Obesity. 39 (10).

R Dugan, M.E., J.L. Aalhus, A.L. Schaefer, et al. (1997). The effect of conjugated linoleic acid on fat to lean repartitioning and feed conversion in pigs. Canadian Journal of Animal Science. 77 (4):723-25.

Read, N.W., A. McFarlane, R.I. Kinsman, et al. (1984). Effect of infusion of nutrient solutions into the ileum on gastrointestinal transit and plasma levels of neurotensin and enteroglucagon. Gastroenterology. 86 (2):274-80.

Rebello, C.J., C.K. Martin, W.D. Johnson, et al. (2012). Efficacy of olibra: a 12-week randomized controlled trial and a review of earlier studies. Journal of Diabetes Science and Technology. 6 (3). Diabetes Technology Society:695-708.

Rees, D., E.A. Miles, T. Banerjee, et al. (2006). Dose-related effects of eicosapentaenoic acid on innate immune function in healthy humans: a comparison of young and older men. The American Journal of Clinical Nutrition. 83:331-42.

Riediger, T., C. Bothe, C. Becskei, et al. (2004). Peptide yy directly inhibits ghrelin-activated neurons of the arcuate nucleus and reverses fasting-induced c-fos expression. 
Neuroendocrinology. 79 (6):317-26.

Risérus, U., P. Arner, K. Brismar, et al. (2002). Treatment with dietary trans10cis12 conjugated linoleic acid causes isomer-specific insulin resistance in obese men with the metabolic syndrome. Diabetes Care. 25 (9):1516-21.

Risérus, U., L. Berglund, and B. Vessby. (2001). Conjugated linoleic acid (cla) reduced abdominal adipose tissue in obese middle-aged men with signs of the metabolic syndrome: a randomised controlled trial. International Journal of Obesity. 25 (8):1129-35.

Rodríguez de Fonseca, F., M. Navarro, R. Gómez, et al. (2001). An anorexic lipid mediator regulated by feeding. Nature. 414 (6860):209-12.

Rolls, B.J., N. Gnizak, A. Summerfelt, et al. (1988). Food intake in dieters and nondieters after a liquid meal containing medium-chain triglycerides. American Journal of Clinical Nutrition. 48 (1):66-71.

Rudkowska, I., C.E. Roynette, I. Demonty, et al. (2005). Diacylglycerol: efficacy and mechanism of action of an anti-obesity agent. Obesity Research. 13 (11):1864-76.

Ruijschop, R.M.A.J., A.E.M. Boelrijk, and M.C. te Giffel. (2008). Satiety effects of a dairy beverage fermented with propionic acid bacteria. International Dairy Journal. 18 (9):945-50.

Sahu, A. (2003). Leptin signaling in the hypothalamus: emphasis on energy homeostasis and leptin resistance. Frontiers in Neuroendocrinology.

Salas-Salvadó, J., F. Márquez-Sandoval, and M. Bulló. (2006). Conjugated linoleic acid intake in humans: a systematic review focusing on its effect on body composition, glucose, and lipid metabolism. Critical Reviews in Food Science and Nutrition. 46 (6):479-88.

Samuel, B.S., A. Shaito, T. Motoike, et al. (2008). Effects of the gut microbiota on host adiposity are modulated by the short-chain fatty-acid binding g protein-coupled receptor, gpr41. Proceedings of the National Academy of Sciences. 105 (43):16767-72.

Santora, J.E., D.L. Palmquist, and K.L. Roehrig. (2000). Nutrient metabolism trans-vaccenic acid is desaturated to conjugated linoleic acid in mice 1. J. Nutr. 130:208-15.

Scharrer, E. (1999). Control of food intake by fatty acid oxidation and ketogenesis. Nutrition (Burbank, Los Angeles County, Calif.). 15 (9):704-14.

Scharrer, E., and W. Langhans. (1986). Control of food intake by fatty acid oxidation. The American Journal of Physiology. 250 (6 Pt 2):R1003-6.

Seimon, R. V, T. Wooster, B. Otto, et al. (2009). The droplet size of intraduodenal fat emulsions influences antropyloroduodenal motility, hormone release, and appetite in healthy males. American Journal of Clinical Nutrition. 89:1729-36.

Shah, M., and A. Vella. (2014). Effects of glp-1 on appetite and weight. Reviews in Endocrine and 
Shelton, V.J., A.G. Shelton, M.J. Azain, et al. (2012). Incorporation of conjugated linoleic acid into brain lipids is not necessary for conjugated linoleic acid-induced reductions in feed intake or body fat in mice. Nutrition Research. 32 (11):827-36.

Silva, A. De, and S.R. Bloom. (2012). Gut hormones and appetite control: a focus on pyy and glp-1 as therapeutic targets in obesity. Gut and Liver. 6 (1):10-20.

Simopoulos, A.P. (2002). Omega-3 fatty acids in inflammation and autoimmune diseases. Journal of the American College of Nutrition. 21 (6). Routledge:495-505.

Smedman, A., and B. Vessby. (2001). Conjugated linoleic acid supplementation in humans-metabolic effects. Lipids. 36 (8):773-81.

Smit, H., E. Keenan, E. Kovacs, et al. (2011). No efficacy of processed fabuless (olibra) in suppressing appetite or food intake. European Journal of Clinical Nutrition. 65 (10):81-86.

Smit, H.J., E. Keenan, E.M.R. Kovacs, et al. (2012). No appetite efficacy of a commercial structured lipid emulsion in minimally processed drinks. International Journal of Obesity. 36 (9):1222-28.

Spiller, R.C., I.F. Trotman, B.E. Higgins, et al. (1984). The ileal brake--inhibition of jejunal motility after ileal fat perfusion in man. Gut. 25 (4). BMJ Group:365-74.

Squires, P.E., R.D. Rumsey, C.A. Edwards, et al. (1992). Effect of short-chain fatty acids on contractile activity and fluid flow in rat colon in vitro. The American Journal of Physiology. 262 (5 Pt 1):G813-7.

St-Onge, M.-P., and P.J.H. Jones. (2002). Physiological effects of medium-chain triglycerides: potential agents in the prevention of obesity. Journal of Nutrition. 132 (3):329-32.

St-Onge, M.-P., B. Mayrsohn, M. O’Keeffe, et al. (2014). Impact of medium and long chain triglycerides consumption on appetite and food intake in overweight men. European Journal of Clinical Nutrition. 68 (10):1134-40.

Stelmach-Mardas, M., T. Rodacki, J. Dobrowolska-Iwanek, et al. (2016). Link between food energy density and body weight changes in obese adults. Nutrients. 8 (4). Multidisciplinary Digital Publishing Institute (MDPI):229.

Stoeckel, L.E., R.E. Weller, M. Giddings, et al. (2008). Peptide yy levels are associated with appetite suppression in response to long-chain fatty acids. Physiology and Behavior. 93 (12):289-95.

Suzuki, M., Y. Shinohara, Y. Ohsaki, et al. (2011). Lipid droplets: size matters. Journal of Electron Microscopy. 60 (1):S101-16.

Taguchi, H., T. Nagao, H. Watanabe, et al. (2001). Energy value and digestibility of dietary oil 

containing mainly 1,3-diacylglycerol are similar to those of triacylglycerol. Lipids. 36 (4):37982.

Tarini, J., and T.M.S. Wolever. (2010). The fermentable fibre inulin increases postprandial serum short-chain fatty acids and reduces free-fatty acids and ghrelin in healthy subjects. Applied Physiology, Nutrition, and Metabolism. 35 (1):9-16.

Tauchi-Sato, K., S. Ozeki, T. Houjou, et al. (2002). The surface of lipid droplets is a phospholipid monolayer with a unique fatty acid composition. Journal of Biological Chemistry. 277 (46):44507-12.

Tolhurst, G., H. Heffron, Y.S. Lam, et al. (2012). Short-chain fatty acids stimulate glucagon-like peptide-1 secretion via the g-protein-coupled receptor ffar2. Diabetes. 61:364-71.

Tsuboyama-Kasaoka, N., M. Takahashi, K. Tanemura, et al. (2000). Conjugated linoleic acid supplementation reduces adipose tissue by apoptosis and develops lipodystrophy in mice. Diabetes. 49:1534-42.

Tsuji, H., M. Kasai, H. Takeuchi, et al. (2001). Dietary medium-chain triacylglycerols suppress accumulation of body fat in a double-blind, controlled trial in healthy men and women. Journal of Nutrition. 131 (11):2853-59.

Vadder, F. De, P. Kovatcheva-Datchary, D. Goncalves, et al. (2014). Microbiota-generated metabolites promote metabolic benefits via gut-brain neural circuits. Cell. 156:84-96.

Volkow, N.D., G.-J. Wang, and R.D. Baler. (2011). Reward, dopamine and the control of food intake: implications for obesity. Trends in Cognitive Sciences. 15 (1). NIH Public Access:3746.

Wahle, K.W.J., S.D. Heys, and D. Rotondo. (2004). Conjugated linoleic acids: are they beneficial or detrimental to health? Progress in Lipid Research. 43 (6):553-87.

Wanders, A.J., J.J.G.C. van den Borne, C. de Graaf, et al. (2011). Effects of dietary fibre on subjective appetite, energy intake and body weight: a systematic review of randomized controlled trials. Obesity Reviews. 12 (9):724-39.

Wanders, A.J., L. Leder, J.D. Banga, et al. (2010). A high intake of conjugated linoleic acid does not affect liver and kidney function tests in healthy human subjects. Food Chemistry and Toxicology. 48 (2):587-90.

Watras, A.C., A.C. Buchholz, R.N. Close, et al. (2007). The role of conjugated linoleic acid in reducing body fat and preventing holiday weight gain. International Journal of Obesity (2005). 31:481-87.

Welch, I., K. Saunders, and N.W. Read. (1985). Effect of ileal and intravenous infusions of fat emulsions on feeding and satiety in human volunteers. Gastroenterology. 89 (6):1293-97. 
1489 1490 1491 1492 1493 1494 1495 1496 1497 1498 1499 1500 1501 1502 1503 1504 1505 1506 1507 1508 1509 1510 1511 1512 1513 1514 1515 1516 1517 1518 1519 1520 1521

WHO. (2000). Obesity: preventing and managing the global epidemic. report of a who consultation. who technical report series no. 894. WHO. Geneva: World Health Organization.

Williams CM., and Kirkham TC. (1999). Anandamide induces overeating: mediation by central cannabinoid (cb1) receptors. Psychopharmacology. 143 (3):315-17.

Wong, M.W., B.P. Chew, T.S. Wong, et al. (1997). Effects of dietary conjugated linoleic acid on lymphocyte function and growth of mammary tumors in mice. Anticancer Research. 17 (2A):987-93.

Wood, J.T., J.S. Williams, L. Pandarinathan, et al. (2010). Dietary docosahexaenoic acid supplementation alters select physiological endocannabinoid-system metabolites in brain and plasma. Journal of Lipid Research. 51:1416-23.

Wymelbeke, V. Van, A. Himaya, J. Louis-Sylvestre, et al. (1998). Influence of medium-chain and long-chain triacylglycerols on the control of food intake in men. American Journal of Clinical Nutrition. 68 (2):226-34.

Wymelbeke, V. Van, J. Louis-Sylvestre, and M. Fantino. (2001). Substrate oxidation and control of food intake in men after a fat-substitute meal compared with meals supplemented with an isoenergetic load of carbohydrate, long-chain triacylglycerols, or medium-chain triacylglycerols. American Journal of Clinical Nutrition. 74 (5):620-30.

Wynne, K., S. Stanley, B. Mcgowan, et al. (2005). Appetite control. Journal of Endocrinology. 184:291-318.

Xu, T., X. Li, Z. Zhang, et al. (2008). Effect of diacylglycerol on body weight: a meta-analysis. Asia Pacific Journal of Clinical Nutrition. 17 (3):415-21.

Yamamoto, K., H. Asakawa, K. Tokunaga, et al. (2001). Long-term ingestion of dietary diacylglycerol lowers serum triacylglycerol in type ii diabetic patients with hypertriglyceridemia. The Journal of Nutrition. 131 (12):3204-7.

Yasunaga, K., W.H. Glinsmann, Y. Seo, et al. (2004). Safety aspects regarding the consumption of high-dose dietary diacylglycerol oil in men and women in a double-blind controlled trial in comparison with consumption of a triacylglycerol control oil. Food and Chemical Toxicology. 42 (9):1419-29.

Yehuda, S., S. Rabinovitz, and D.I. Mostofsky. (2005). Mixture of essential fatty acids lowers test anxiety. Nutritional Neuroscience. 2005.

Zaid, Z.A., S. Suzana, A.R.A. Jamal, et al. (2012). Fish oil supplementation is beneficial on caloric intake, appetite and mid upper arm muscle circumference in children with leukaemia. Asia Pac J Clin Nutr. 21 (4):502-10.

Zhang, Y., Y. Kuang, K. Xu, et al. (2013). Ketosis proportionately spares glucose utilization in 
Table 1. Studies on the effect of medium chain triglycerides (MCT) on satiety

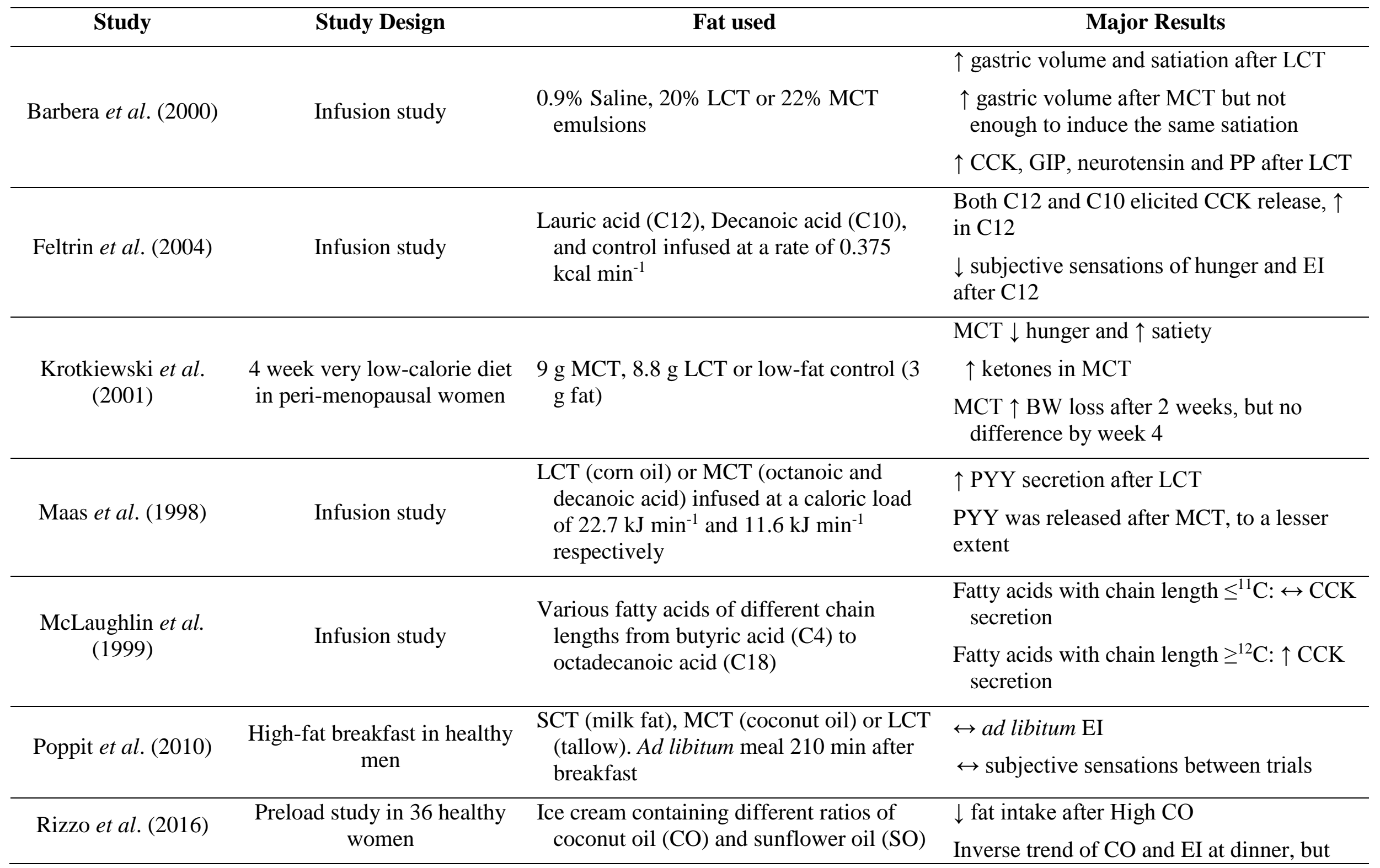




\begin{tabular}{|c|c|c|c|}
\hline & & $\begin{array}{l}\text { High CO: } 75 \% \mathrm{CO}: 25 \% \mathrm{SO} \\
\text { Equal: } 50: 50 \\
\text { High SO: } 75 \% \mathrm{SO}: 25 \% \mathrm{CO}\end{array}$ & $\begin{array}{l}\text { non-significant } \\
\leftrightarrow \text { EI between trials }\end{array}$ \\
\hline Rolls et al. (1988) & $\begin{array}{l}\text { Preload study in } 24 \text { women, } \\
12 \text { dieters, and } 12 \text { non- } \\
\text { dieters }\end{array}$ & $\begin{array}{l}30 \% \text { fat liquid preload of which all } 30 \% \\
\text { LCT or } 24 \% \text { MCT and } 6 \% \text { LCT } \\
3 \text { doses of each providing 100, } 200 \text { or } \\
\text { 300kcal }\end{array}$ & $\begin{array}{l}\downarrow \text { ad libitum EI after MCT } \\
\text { Larger doses led to } \downarrow \text { EI } \\
\leftrightarrow \text { subjective sensations } \\
\text { No consistent pattern emerged in dieters }\end{array}$ \\
\hline St-Onge et al. (2014) & $\begin{array}{l}2 \text { studies: one breakfast } \\
\text { study and one preload study. }\end{array}$ & $\begin{array}{l}\text { Both studies: breakfast containing } 20 \mathrm{~g} \text { of } \\
\text { either MCT or LCT (corn oil) } \\
\text { Preload study: } 3 \mathrm{~h} \text { after breakfast } \\
\text { participants consumed a preload yoghurt } \\
\text { containing an extra } 10 \mathrm{~g} \text { of either oil. }\end{array}$ & $\begin{array}{l}\downarrow \text { intake at ad lib lunch after MCT } \\
\uparrow \text { PYY and leptin after MCT } \\
\leftrightarrow \text { total ghrelin and GLP-1 } \\
\uparrow \text { suppression after preload as opposed to } \\
\text { the breakfast }\end{array}$ \\
\hline $\begin{array}{c}\text { Van Wymelbeke et } \\
\text { al. (1998) }\end{array}$ & $\begin{array}{l}\text { High carbohydrate breakfast } \\
\text { in } 12 \text { healthy volunteers }\end{array}$ & $\begin{array}{l}4 \text { high CHO breakfast with either } 70 \mathrm{~kJ} \text { fat } \\
\text { substitute, or } 1460 \mathrm{~kJ} \text { from different fats: } \\
\text { saturated LCT (from } 42 \mathrm{~g} \text { lard), } \\
\text { monounsaturated LCT (from } 40 \mathrm{~g} \text { olive } \\
\text { oil) or MCT (from } 43 \mathrm{~g} \text { of Ceres MCT } \\
\text { oil). }\end{array}$ & $\begin{array}{l}\downarrow \text { hunger after MCT } \\
\leftrightarrow \text { in time to request lunch other than } \downarrow \text { in } \\
\text { fat substitute } \\
\leftrightarrow \text { in time to request dinner }\end{array}$ \\
\hline $\begin{array}{l}\text { Van Wymelbeke, } \\
\text { Louis-Sylvester and } \\
\text { Fantino (2001) }\end{array}$ & Preload lunch in 10 men & $\begin{array}{l}4 \text { lunches: } \\
2310 \mathrm{~kJ} \text { meal containing } 40 \mathrm{~kJ} \text { fat } \\
\text { substitute (Sub), } 32 \mathrm{~g} \mathrm{LCT}, 35 \mathrm{~g} \mathrm{MCT} \mathrm{or} \\
53 \mathrm{~g} \mathrm{CHO} \text { and } 8 \mathrm{~g} \mathrm{LCT} \mathrm{(CHO)}\end{array}$ & $\begin{array}{l}\uparrow \text { delay in meal request in } \mathrm{CHO} \\
\uparrow \text { delay in MCT over LCT and Sub, but not } \\
\text { as long as CHO } \\
\downarrow \text { EI in MCT }\end{array}$ \\
\hline \multicolumn{4}{|c|}{$\begin{array}{l}\text { MCT: Medium-chain triglycerides; LCT: Long-chain triglycerides; EI: Energy Intake; CCK: Cholecystokinin; GIP: Gastric Inhibitory Peptide; } \\
\text { PP: Pancreatic Polypeptide; BW: Body Weight; CHO: Carbohydrate. } \uparrow \text { shows increased or greater } \downarrow \text { shows decreased or lesser } \leftrightarrow \text { shows no } \\
\text { change or difference. }\end{array}$} \\
\hline
\end{tabular}



1530
1531
1532
1533
1534
1535
1536
1537
1538
1539
1540
1541
1542
1543
1544
1545
1546
1547
1548
1549
1550
1551 
Table 2. Studies on the effect of conjugated linoleic acids on satiety

\begin{tabular}{|c|c|c|c|}
\hline Study & Study Design & Fat used & Major Results \\
\hline $\begin{array}{l}\text { Blankson et al. } \\
\quad(2000)\end{array}$ & $\begin{array}{l}12 \text { weeks supplementation } \\
\text { study }\end{array}$ & $\begin{array}{l}\text { CLA capsules: } 75 \% \text { CLA, equal parts } \\
\text { c9,t11 and t10,c12 isomers } \\
\text { Placebo capsules: olive oil } \\
\text { Varying dosages: Placebo: } 9 \mathrm{~g} \text { olive oil. } \\
\text { CLA doses of } 1.7 \mathrm{~g}, 3.4 \mathrm{~g}, 5.1 \mathrm{~g} \text { or } 6.8 \mathrm{~g}\end{array}$ & $\begin{array}{l}\downarrow \text { Appetite after } 12 \text { week period in } 3.4 \mathrm{~g} \text { and } \\
\quad 7.8 \mathrm{~g} \text { CLA groups } \\
\uparrow \text { Lean mass after all CLA doses. }\end{array}$ \\
\hline $\begin{array}{l}\text { Coleman, Quinn and } \\
\text { Clegg (2016) }\end{array}$ & Preload breakfast in 19 men & $\begin{array}{l}22 \mathrm{~g} \text { vegetable oil (control) } \\
5 \mathrm{~g} \text { CLA and } 16 \mathrm{~g} \text { vegetable oil (CLA) } \\
25 \mathrm{~g} \mathrm{MCT} \mathrm{oil} \mathrm{(MCT)}\end{array}$ & $\begin{array}{l}\downarrow \text { (non-sig) EI at ad libitum lunch in both } \\
\text { CLA and MCT } \\
\downarrow \text { Overall EI in MCT } \\
\uparrow \text { Time to meal request in CLA }\end{array}$ \\
\hline Cornish et al. (2009) & $\begin{array}{l}\text { 5-week strength training, } 69 \\
\text { participants }\end{array}$ & $\begin{array}{l}3 \text { groups: } \\
6 \mathrm{~g} \cdot \text { day CLA }(36.1 \% \mathrm{c} 9, \mathrm{t} 11 \text { and } 36.3 \% \\
\text { t10,c12 isomers), } 36 \mathrm{~g} \cdot \text { day whey and } 9 \\
\mathrm{~g} \cdot \mathrm{d} \text { creatine }(\mathrm{CPP}) \\
36 \mathrm{~g} \cdot \text { day whey, } 9 \mathrm{~g} \cdot \mathrm{d} \text { creatine and placebo } \\
\text { oil }(\mathrm{CP}) \\
\text { Placebo oil (P) }\end{array}$ & $\begin{array}{l}\leftrightarrow \text { EI in all groups from baseline to } 12 \\
\text { weeks and between groups from self- } \\
\text { reported diet diary data }\end{array}$ \\
\hline Gaullier et al. (2005) & $\begin{array}{l}2 \text { year CLA supplementation } \\
\text { study }\end{array}$ & $\begin{array}{l}4.5 \mathrm{~g} \cdot \mathrm{d} \text { olive oil (Placebo) } \\
4.5 \mathrm{~g} \cdot \mathrm{d} \text { Triglyceride CLA (CLA-TG) } \\
\text { providing } 3.4 \mathrm{~g} \text { active isomers } \\
4.5 \mathrm{~g} \cdot \mathrm{d} \text { Free fatty acid CLA (CLA-FA) } \\
\text { providing } 3.6 \mathrm{~g} \text { active isomers }\end{array}$ & $\begin{array}{l}\downarrow \text { EI by } 1289 \mathrm{~kJ} \cdot \text { day in CLA-TG } \\
\downarrow \text { EI by } 870 \mathrm{~kJ} \cdot \text { day in CLA-FFA } \\
\downarrow \text { Leptin both CLA-TG and CLA-FFA }\end{array}$ \\
\hline Iwata et al. (2007) & $\begin{array}{l}12 \text { weeks supplementation in } \\
60 \text { healthy volunteers }\end{array}$ & $\begin{array}{l}5.4 \mathrm{~g} \text { CLA-triacylglycerol ( } 3.4 \mathrm{~g} \text { as CLA } \\
\text { isomers) } \\
10.8 \mathrm{~g} \mathrm{CLA} \text { - triacylglycerol ( } 6.8 \mathrm{~g} \text { as CLA }\end{array}$ & $\begin{array}{l}\leftrightarrow \text { In energy intake after treatment: no } \\
\text { effect of CLA on satiety } \\
\uparrow \text { Leptin in all groups (including placebo) }\end{array}$ \\
\hline
\end{tabular}


isomers)

Placebo (10.8 g safflower oil)

CLA comprised 50:50 c9,t11 and t10,c12 isomers

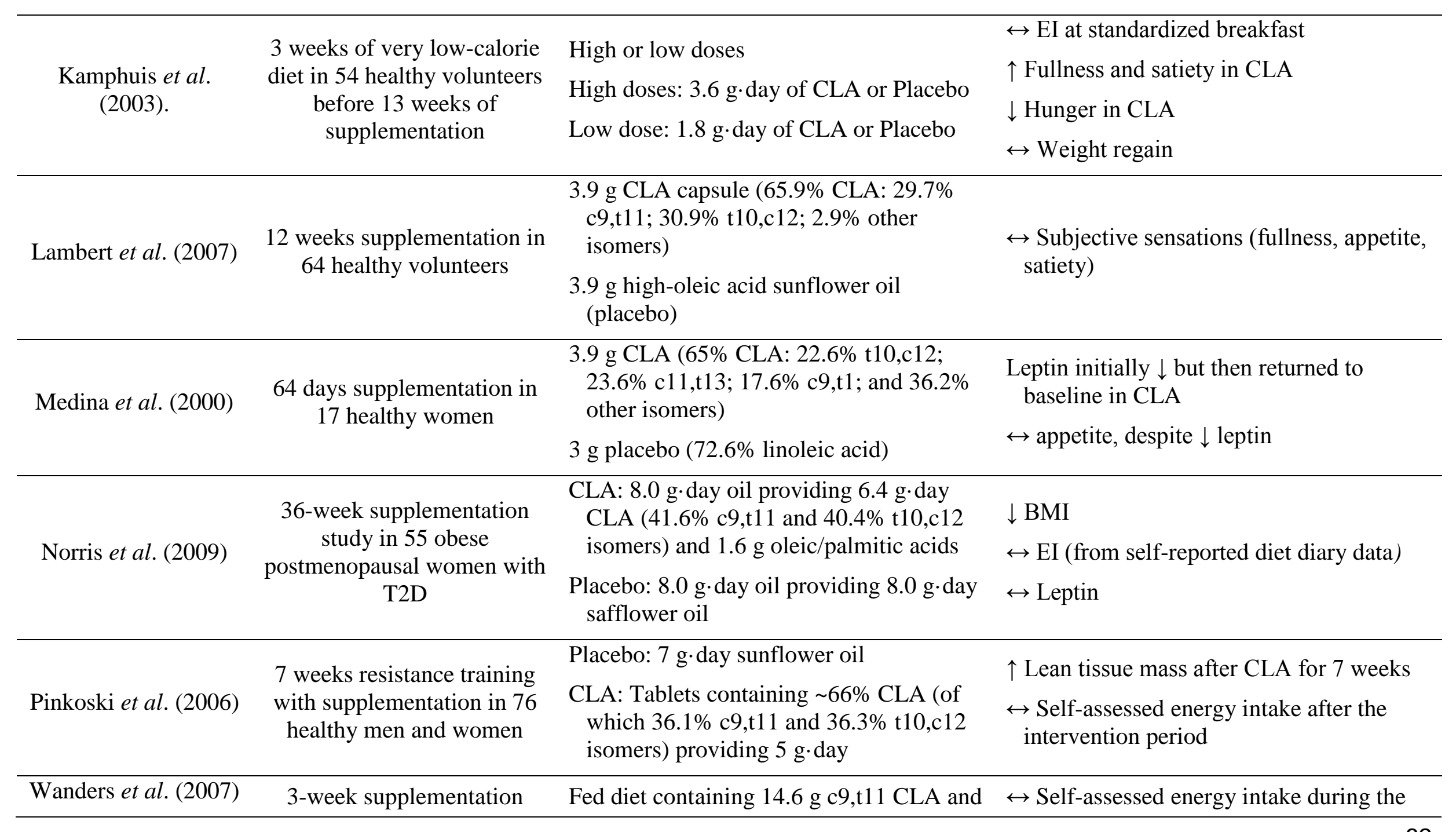



isomers

Watras et al. (2007)

6-month supplementation study
CLA: $4 \mathrm{~g}$. day of oil providing $3.2 \mathrm{~g}$ - day CLA $(39.2 \% \mathrm{c} 9, \mathrm{t} 11$ and $38.5 \% \mathrm{t} 10, \mathrm{c} 12)$

\section{CLA}

$\leftrightarrow$ EI during EI, whilst EI $\uparrow$ in placebo

CLA: Conjugated Linoleic Acid; EI: Energy Intake; CCK: Cholecystokinin; GIP: Gastric Inhibitory Peptide; PP: Pancreatic Polypeptide; BW:

Body Weight. $\uparrow$ shows increased or greater $\downarrow$ shows decreased or lesser $\leftrightarrow$ shows no change or difference.

1552

1553

1554

1555

1556

1557

1558

1559

1560

1561

1562

1563

1564

1565

1566

1567

1568 
Table 3. Studies on the effect of short-chain fatty acids on satiety

\begin{tabular}{|c|c|c|c|}
\hline Study & Study Design & Fat used & Major Results \\
\hline Cani et al. (2006) & $\begin{array}{c}2 \times 2 \text {-week crossover with } \\
10 \text { healthy subjects }\end{array}$ & $\begin{array}{l}16 \mathrm{~g} \cdot \text { day oligofructose }(\mathrm{OF}) \\
16 \mathrm{~g} \cdot \text { day placebo (PLA) } \\
\text { Two-week washout between each. }\end{array}$ & $\begin{array}{l}\uparrow \text { satiety after breakfast with OF intake } \\
\downarrow \text { intake at breakfast and lunch after } 2 \\
\text { weeks of OF } \\
\downarrow \text { overall EI in OF }\end{array}$ \\
\hline $\begin{array}{l}\text { Chambers et al. } \\
\text { (2015) }\end{array}$ & $\begin{array}{c}24 \text { weeks parallel in } 60 \\
\text { subjects }\end{array}$ & $\begin{array}{l}10 \mathrm{~g} \cdot \text { day inulin-propionate }(\mathrm{IP}) \\
10 \mathrm{~g} \cdot \text { day of inulin-control }(\mathrm{CON})\end{array}$ & $\begin{array}{l}\uparrow \text { PYY and GLP-1 release after IP } \\
\downarrow \text { EI after IP by } 14 \% \\
\leftrightarrow \text { Subjective sensations }\end{array}$ \\
\hline $\begin{array}{l}\text { Darwiche et al. } \\
\text { (2001). }\end{array}$ & $\begin{array}{l}\text { Breakfast study in } 9 \text { healthy } \\
\text { volunteers }\end{array}$ & $\begin{array}{l}\text { Control bread made with basic recipe, or } \\
\text { same bread with the addition of sodium } \\
\text { propionate }\end{array}$ & $\downarrow$ GE after bread containing propionate \\
\hline $\begin{array}{l}\text { Darzi, Frost and } \\
\text { Robertson (2012) }\end{array}$ & $\begin{array}{c}\text { Breakfast study in } 20 \text { healthy } \\
\text { unrestrained eaters }\end{array}$ & $\begin{array}{l}\text { Sandwiches made with a propionate rich } \\
\text { sourdough to yield } 4.8 \mathrm{mmol} \text { propionate } \\
\text { per } 100 \mathrm{~g} \text { of bread or a control } \\
\text { equivalent }\end{array}$ & $\begin{array}{l}\leftrightarrow \text { EI at } a d \text { lib lunch between trials } \\
\leftrightarrow 24 \text { h EI between trials } \\
\leftrightarrow \text { Appetite ratings }\end{array}$ \\
\hline Darzi et al. (2014) & $\begin{array}{l}2 \text { studies investigating the } \\
\text { oral properties of SCFA }\end{array}$ & $\begin{array}{l}\text { Study 1: } \\
\text { Control drink: } 75 \mathrm{~g} \text { in } 275 \mathrm{~g} \text { water across } \\
\text { two drinks } \\
\text { Unpalatable drink: } 25 \mathrm{~g} \text { vinegar and } 25 \mathrm{~g} \\
\text { squash in } 100 \mathrm{~g} \text { water followed by } 50 \mathrm{~g} \\
\text { squash in } 100 \mathrm{~g} \text { water } \\
\text { Palatable drink: } 25 \mathrm{~g} \text { vinegar and } 75 \mathrm{~g} \\
\text { squash in } 250 \mathrm{~g} \text { water across two drinks } \\
\text { Study 2: }\end{array}$ & $\begin{array}{l}\text { Study 1: } \\
\uparrow \text { Nausea after unpalatable drink } \\
\downarrow \begin{array}{l}\downarrow \text { ad lib and } 24 \text { h EI after vinegar } \\
\text { treatments }\end{array} \\
\text { Study 2: } \\
\downarrow \text { Pleasantness after vinegar drink } \\
\leftrightarrow \text { Nausea ratings }\end{array}$ \\
\hline
\end{tabular}




$\begin{array}{ll}\text { Modified sham feeding of a control drink } & \leftrightarrow \text { Appetite ratings } \\ \text { (180g water) or a vinegar drink (230g } & \leftrightarrow \text { EI at ad lib meal } \\ \text { white wine vinegar in } 150 \mathrm{~g} \text { water }) & \end{array}$

\begin{tabular}{|c|c|c|c|}
\hline & & & $\uparrow$ acetate concentrations after OF \\
\hline Daud et al. (2014) & $\begin{array}{c}6 \text { weeks parallel in } 22 \\
\text { subjects }\end{array}$ & $\begin{array}{l}30 \mathrm{~g} \cdot \text { day oligofructose }(\mathrm{OF}) \\
30 \mathrm{~g} \cdot \text { day cellulose }(\mathrm{CON})\end{array}$ & $\begin{array}{l}\uparrow \text { fasting serum propionate and butyrate } \\
\text { after OF } \\
\uparrow \text { PYY AUC after OF } \\
\uparrow \text { GLP-1 AUC after CON } \\
\downarrow \text { EI and hunger after OF }\end{array}$ \\
\hline Frost et al. (2014) & Series of tests in mice & ${ }^{11} \mathrm{C}$ Acetate injections & $\begin{array}{l}\downarrow \text { EI } \\
\downarrow \text { agouti-related peptide expression } \\
\uparrow \text { proopiomelacocortin expression }\end{array}$ \\
\hline Jouët et al. (2013) & Perfusion study in 20 healthy & SCFA mixture: $66 \%$ acetic acid, $24 \%$ & $\leftrightarrow$ colonic motility \\
\hline
\end{tabular}




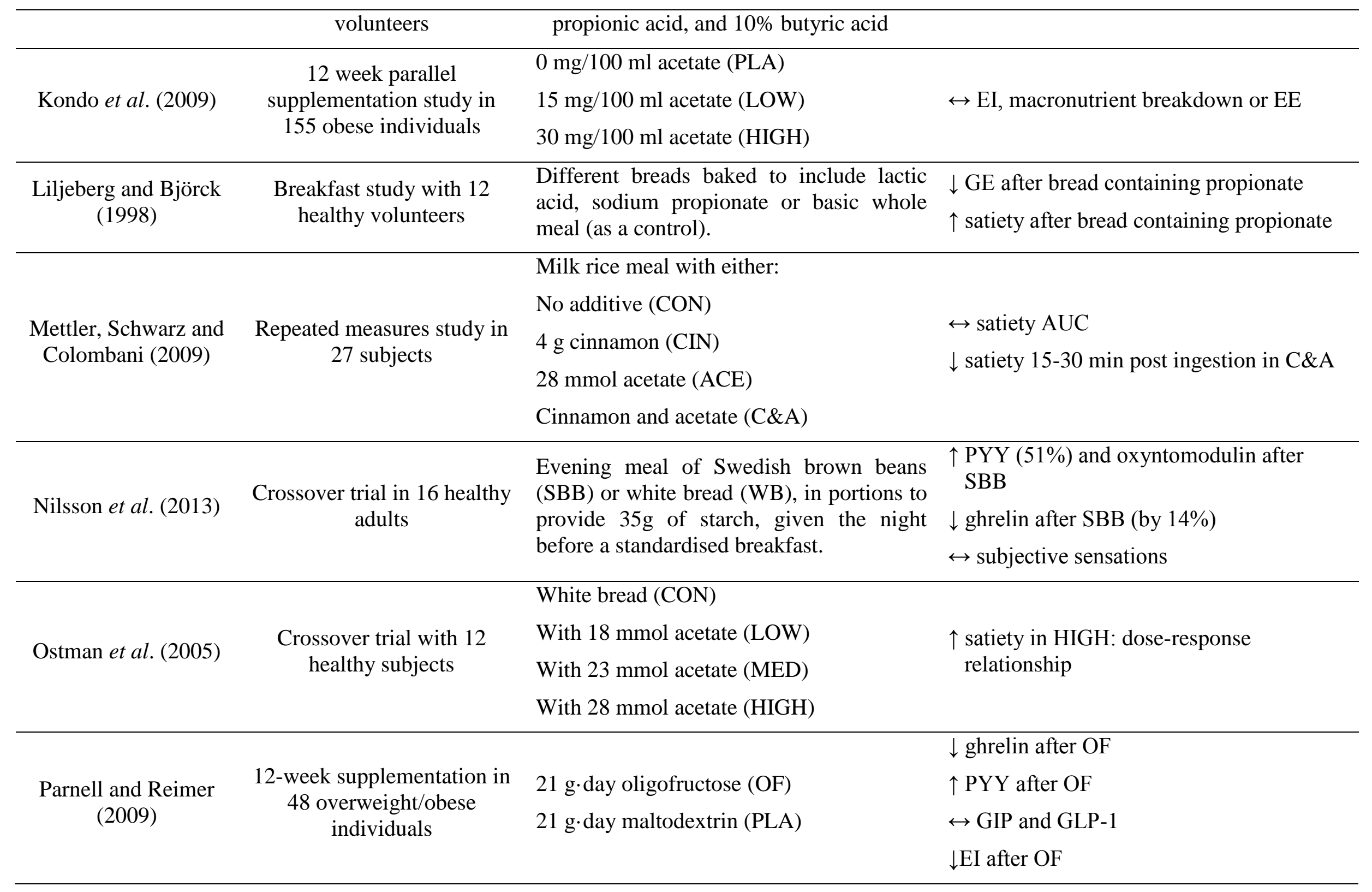




\begin{tabular}{|c|c|c|c|}
\hline \multirow{3}{*}{$\begin{array}{l}\text { Ruijschop et al. } \\
\text { (2008) }\end{array}$} & \multirow{3}{*}{$\begin{array}{l}\text { Preload study in } 43 \text { healthy } \\
\text { women }\end{array}$} & Non-fermented dairy beverage (placebo) & \multirow{3}{*}{$\begin{array}{l}\uparrow \text { fullness after fermented and non- } \\
\text { fermented beverage with addition of } \\
\text { calcium propionate } \\
\leftrightarrow \text { Ad lib EI between all conditions }\end{array}$} \\
\hline & & Fermented dairy beverage & \\
\hline & & $\begin{array}{l}\text { Non-fermented beverage with the addition } \\
\text { of } 0.6 \% \text { calcium propionate }\end{array}$ & \\
\hline \multirow{5}{*}{$\begin{array}{l}\text { Tarini and Wolver } \\
\text { (2010) }\end{array}$} & \multirow{5}{*}{$\begin{array}{l}\text { Acute feeding study in } 12 \\
\text { healthy participants }\end{array}$} & Three test drinks: & \multirow{5}{*}{$\begin{array}{l}\uparrow \text { serum SCFA concentrations after inulin } \\
\text { ingestion } \\
\downarrow \text { ghrelin after inulin } \\
\leftrightarrow \text { GIP and GLP-1 between inulin and } 80 \mathrm{~g} \\
\text { high fructose corn syrup drinks }\end{array}$} \\
\hline & & $80 \mathrm{~g}$ high fructose corn syrup & \\
\hline & & $56 \mathrm{~g}$ high fructose corn syrup and $24 \mathrm{~g}$ & \\
\hline & & inulin & \\
\hline & & $56 \mathrm{~g}$ high fructose corn syrup & \\
\hline
\end{tabular}

1569

1570

1571

1572

1573

1574

1575

1576

1577

1578

1579

1580

1581 
Table 4. Studies on the effect of diacylglycerol on satiety

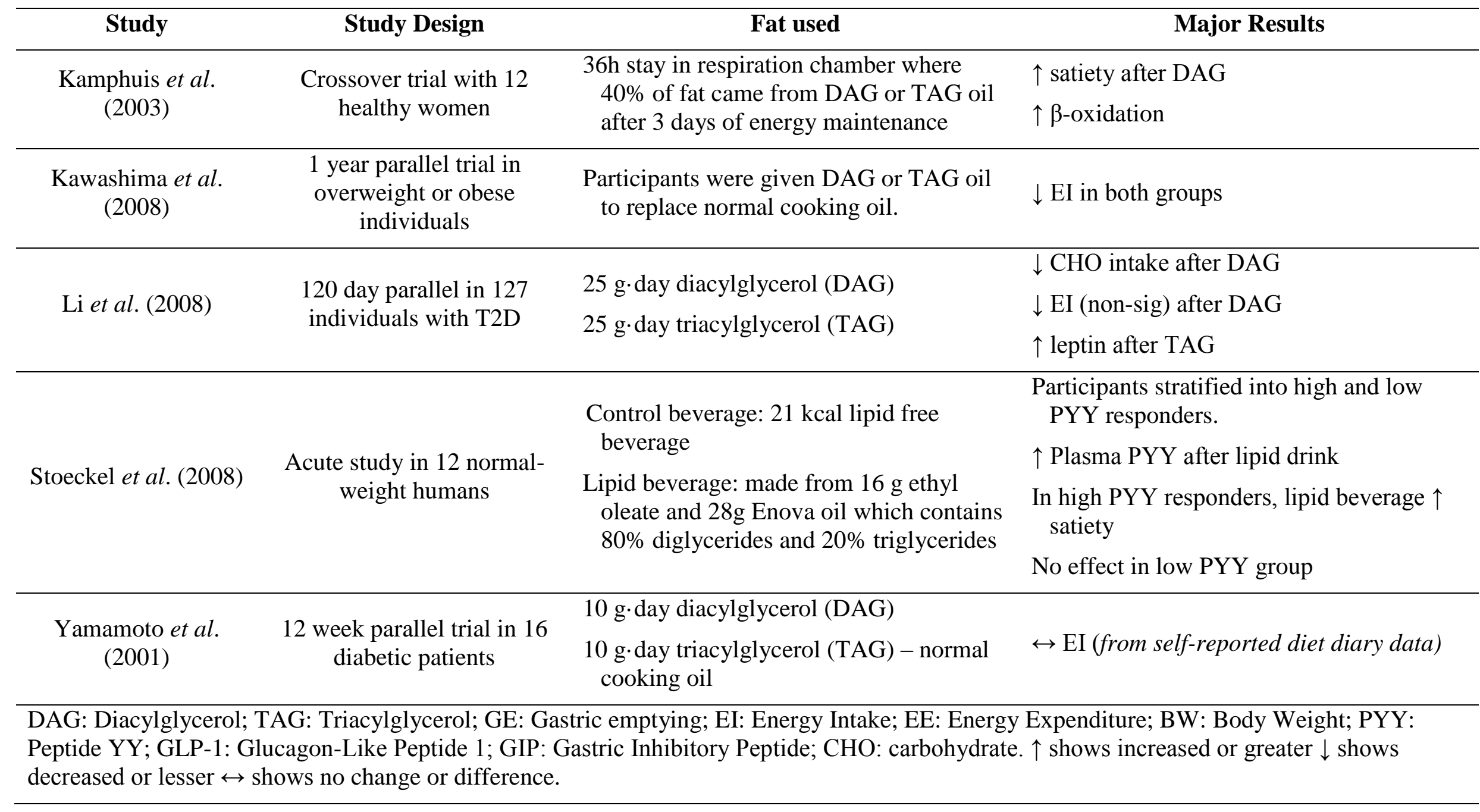


Table 5. Studies on the effect of omega-3 polyunsaturated acids on satiety

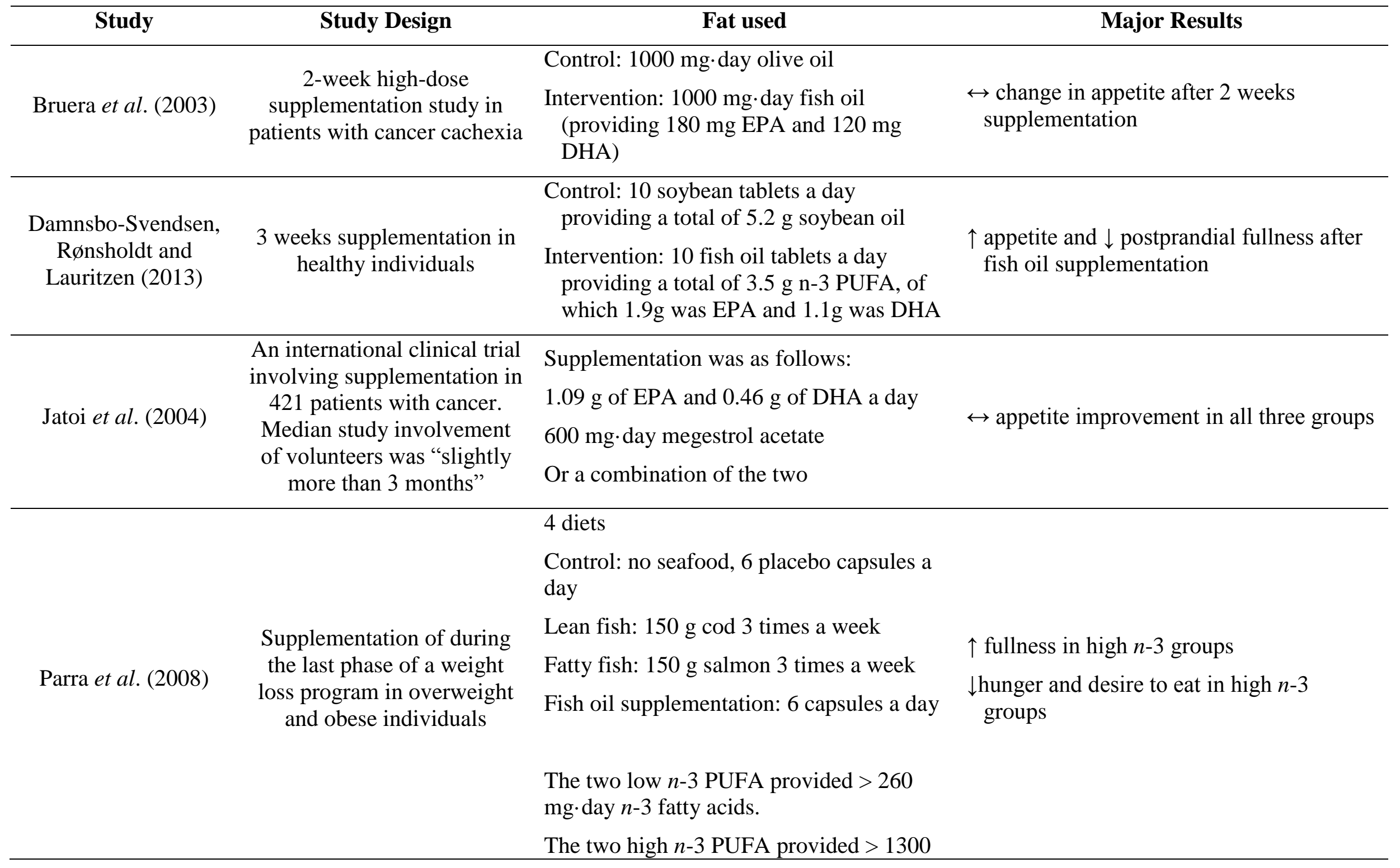


mg. day $n-3$ fatty acids.

\begin{tabular}{|c|c|c|c|}
\hline $\begin{array}{c}\text { Yehunda, Rabinovitz } \\
\text { and Mostofsky } \\
(2005)\end{array}$ & $\begin{array}{l}\text { 3-week supplementation } \\
\text { study in students }\end{array}$ & $\begin{array}{l}33 \text { students in control group received a } \\
\text { placebo "mineral oil" } \\
88 \text { students took Awake (TransCulture, } \\
\text { Japan tables containing } n-3 \text { and } n-6 \text { in a } \\
\text { ratio of } 1: 4\end{array}$ & $\begin{array}{l}\uparrow \text { appetite after supplementation with the } \\
\text { mixture of lipids }\end{array}$ \\
\hline Zaid et al. (2012) & $\begin{array}{l}\text { 8-week supplementation } \\
\text { study in } 51 \text { children with } \\
\text { leukaemia }\end{array}$ & $\begin{array}{l}2 \text { groups: } \\
\text { Control group that received individualised } \\
\text { dietary advice } \\
\text { Trial group that received individualised } \\
\text { dietary advice alongside fish oil } \\
\text { supplementation: } \\
1 \text { x } 1200 \mathrm{mg} \text { capsule per day containing } \\
360 \mathrm{mg} \text { EPA and } 240 \mathrm{mg} \text { DHA }\end{array}$ & $\begin{array}{l}\uparrow \text { appetite in children with leukaemia } \\
\uparrow \text { energy intake over control group }\end{array}$ \\
\hline
\end{tabular}

EPA: eicosapentaenoic acid; DHA: docosahexaenoic acid; PUFA: polyunsaturated fatty acids. $\uparrow$ shows increased or greater $\downarrow$ shows decreased or lesser $\leftrightarrow$ shows no change or difference. 
Table 6. Studies on the effect of small particle lipids on satiety

\begin{tabular}{|c|c|c|c|}
\hline Study & Study Design & Fat used & Major Results \\
\hline Burns et al. (2000) & $\begin{array}{l}\text { Acute feeding study in two } \\
\text { groups of } 30 \text { volunteers }\end{array}$ & $\begin{array}{l}\text { Control: Yoghurt containing } 6 \mathrm{~g} \text { dairy fat } \\
\text { Test: Yoghurt containing } 5 \mathrm{~g}^{\text {Olibra }}{ }^{\mathrm{TM}} \text { and } \\
1 \mathrm{~g} \text { dairy fat }\end{array}$ & $\begin{array}{l}\downarrow \text { Energy intake, food intake, and intake of } \\
\text { all macronutrients after test food at } 4 \mathrm{~h} \\
\leftrightarrow \text { subjective sensations of appetite and } \\
\text { hunger }\end{array}$ \\
\hline Burns et al. (2001) & $\begin{array}{l}\text { Breakfast study in healthy } \\
\text { weight, overweight and } \\
\text { obese participants }\end{array}$ & $\begin{array}{l}\text { Control: Yoghurt containing } 6 \mathrm{~g} \text { dairy fat } \\
\text { Test: Yoghurt containing } 5 \mathrm{~g}^{\text {Olibra }^{\mathrm{TM}}} \text { and } \\
1 \mathrm{~g} \text { dairy fat }\end{array}$ & $\begin{array}{l}\downarrow \text { fat, carbohydrate, protein and total energy } \\
\text { intake at both } 4 \mathrm{~h} \text { and } 8 \mathrm{~h} \text { after test } \\
\text { infusion across all groups } \\
\leftrightarrow \text { Obese intake at } 4 \mathrm{~h} \\
\downarrow \text { Obese intake at } 8 \mathrm{~h} \\
\leftrightarrow \text { subjective sensations of appetite and } \\
\text { hunger }\end{array}$ \\
\hline Burns et al. (2002) & $\begin{array}{c}\text { Breakfast study in } 50 \text { healthy } \\
\text { individuals }\end{array}$ & $\begin{array}{l}\text { Yoghurt with varying doses of Olibra }{ }^{\mathrm{TM}} \text { : } \\
0 \mathrm{~g} \text { (control), } 5 \mathrm{~g}, 10 \mathrm{~g} \text {, or } 15 \mathrm{~g} .5 \text { and } 10 \\
\mathrm{~g} \text { amounts also had } 10 \text { and } 5 \mathrm{~g} \text { of milk } \\
\text { fat, respectively, whereas the control } \\
\text { was } 15 \mathrm{~g} \text { of milk fat. }\end{array}$ & $\begin{array}{l}\uparrow \text { suppression with food intake as dose of } \\
\text { Olibra }^{\mathrm{TM}} \text { increased } \\
\leftrightarrow \text { subjective sensations of appetite and } \\
\text { hunger }\end{array}$ \\
\hline Chan et al. (2012) & $\begin{array}{l}\text { Acute crossover feeding } \\
\text { study }\end{array}$ & $\begin{array}{l}4.2 \mathrm{~g} \text { lipids from a control or } 15 \mathrm{~g} \text { of } \\
\text { Fabuless }{ }^{\mathrm{TM}} \text { provided in (or alongside) } \\
\text { liquid form, semi-solid form and solid } \\
\text { form, with a control for each state: } \\
\text { Liquid emulsion (LE) } \\
\text { Liquid control (LC) } \\
\text { Semi-solid emulsion (LE + Yoghurt) } \\
\text { Semi-solid control (LC + Yoghurt) } \\
\text { Solid emulsion (LE + Muffin) }\end{array}$ & $\begin{array}{l}\uparrow \text { fullness after LE }+ \text { Yoghurt, no effect of } \\
\text { Fabuless }^{\mathrm{TM}} \text { in liquid or solid form } \\
\leftrightarrow \text { EI across all conditions }\end{array}$ \\
\hline
\end{tabular}


Solid control (LC + Muffin)

6 conditions, 4 lipids and 2 controls:

Fabuless $^{\mathrm{TM}}$ emulsion

Dairy emulsion with dairy emulsifier

Chan et al. (2017)

Acute crossover feeding study
Dairy emulsion with soy lecithin emulsifier

Dairy control (non-emulsified)

Palmolein emulsion with dairy emulsifier

Palmolein control (non-emulsified) $\leftrightarrow$ satiety ratings between lipids and respective controls

$\leftrightarrow$ EI between lipids and respective controls
Control: $500 \mathrm{~g}$ of yoghurt containing $10 \mathrm{~g}$ milk fat, split into 2 doses

18-week weight maintenance and dietary manipulation in 50 overweight women
Test: $500 \mathrm{~g}$ of yoghurt containing $6 \mathrm{~g}$ milk fat and $4 \mathrm{~g}$ vegetable fat from Olibra ${ }^{\mathrm{TM}}$, split into 2 doses

\section{3 emulsions:}

Control: Coarse emulsion ( $6 \mu \mathrm{m}$ droplets)

Hussein et al. (2014)

Crossover feeding study in 11 healthy people

Coarse+LBG: Coarse emulsion $(6 \mu \mathrm{m}$ droplets) $+0.5 \%$ locust bean gum

Fine+LBG: Fine emulsion $(0.4 \mu \mathrm{m}$ droplets) $+0.5 \%$ locust bean gum $\downarrow$ hunger after test product

$\uparrow$ CCK, GLP-1, and $\beta$ HB after test product $\downarrow$ weight regain after test product

$\downarrow$ GE after LBG, of which Fine+LBG $\downarrow$ the most

$\uparrow$ CCK after both LBG trials, no diff between Coarse+LBG and Fine+LBG

$\downarrow$ EI after both LBG trials, greater $\downarrow$ after Fine+LBG compared to Coarse+LBG

$\leftrightarrow \mathrm{VAS}$ dairy fat

Test: $300 \mathrm{~g}$ of yoghurt containing $8.5 \mathrm{~g}$ of Fabuless $^{\mathrm{TM}}$ emulsion $\uparrow$ Lipids remaining in the jejunum after test perfusion

$\downarrow$ GE after test perfusion

\begin{tabular}{cccc}
\hline Ledeboer et al. & $\begin{array}{c}\text { Randomised crossover study } \\
\text { involving intraduodenal }\end{array}$ & Control: Saline with emulsifier & $\uparrow$ CCK release and gallbladder contraction \\
\hline
\end{tabular}




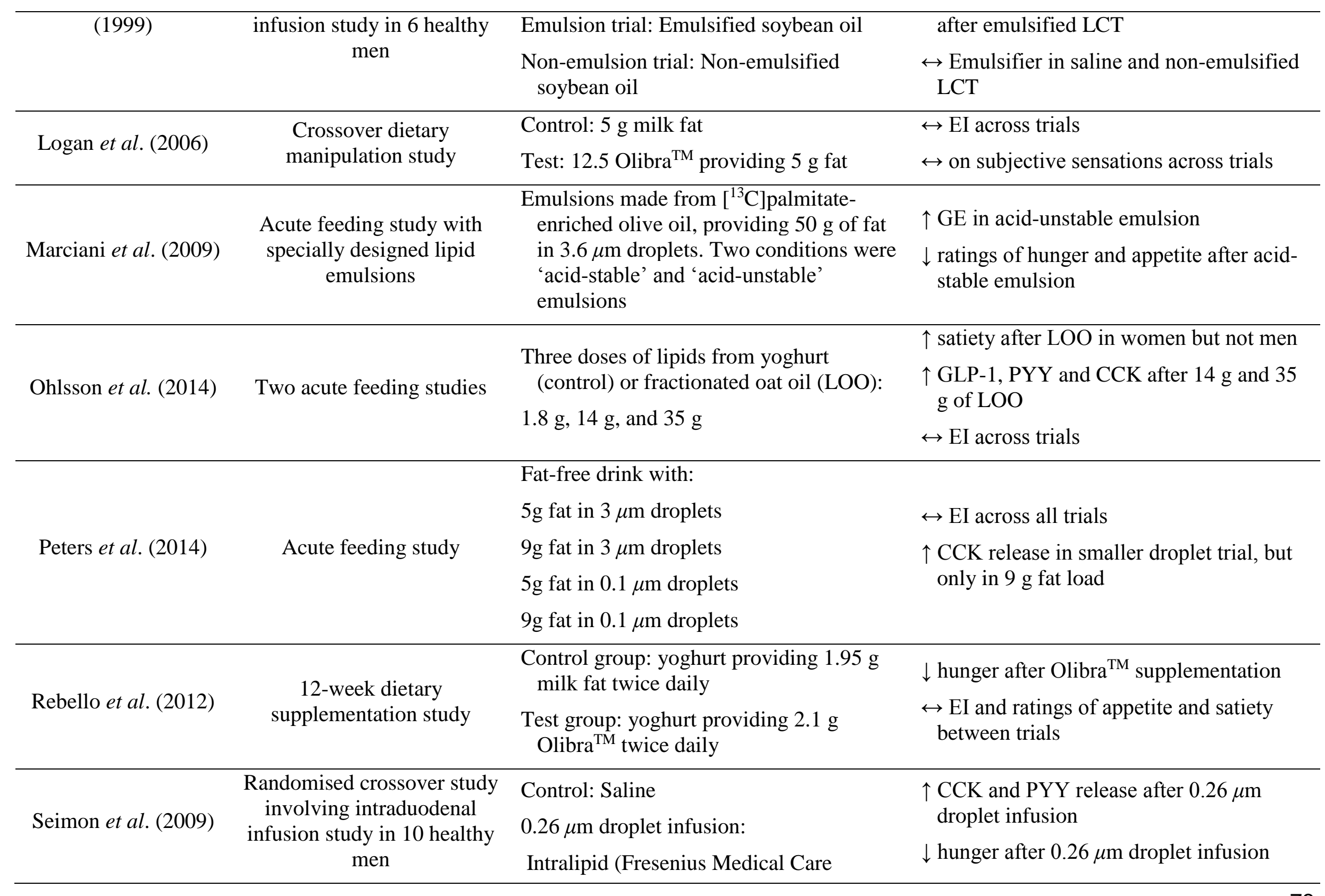




\section{Australia)}

$30 \mu \mathrm{m}$ : Tween 80 , water and canola oil

$170 \mu \mathrm{m}$ : Tween 80 , water and canola oil

Test drinks with $5 \mathrm{~g}$ milk/corn fat added

('Control') or $12.5 \mathrm{~g}$ of Fabuless ${ }^{\mathrm{TM}}$

(containing 5 g of fat) added: $\quad \leftrightarrow$ In EI at ad lib lunch

Smit et al. (2011) Breakfast study in 24 healthy During the manufacturing process

('Processed')

$\downarrow$ In EI at ad lib dinner after Unprocessed

After the manufacturing process

$\leftrightarrow$ on subjective sensations across trials

('Unprocessed')

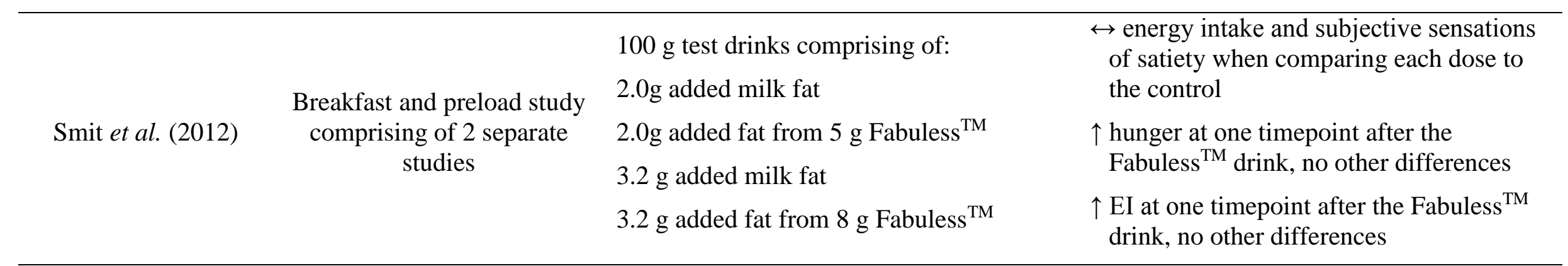

EI: Energy Intake; GE: Gastric Emptying; VAS: Visual Analogue Scale; CCK: Cholecystokinin, GLP-1: Glucagon-Like Peptide 1; $\beta$ HB: $\beta$ -

Hydroxybutyrate. $\uparrow$ shows increased or greater $\downarrow$ shows decreased or lesser $\leftrightarrow$ shows no change or difference. 
Table 7. Summary of the advantages and disadvantages of the functional lipids discussed within this review.

\section{Advantages}

Disadvantages

\section{Medium chain triglycerides}

- Strong potential to mediate satiety(Coleman, Quinn, and Clegg 2016; Rolls et al. 1988; Van Wymelbeke et al. 1998; Van Wymelbeke, Louis-Sylvestre, and Fantino 2001).

- Safe for consumption.

- Possible for effects to be additive with other satiating foods due to hormone-independent effects(Miriam E Clegg 2010).

- Can beneficially alter body composition without altering appetite or satiety(Krotkiewski 2001).
- Repulsive

taste, ecological

validity possibly

questionable(Miriam E Clegg 2010).

- Can cause nausea when ingested in high amounts(Jeukendrup et al. 1998; Goedecke et al. 2005).

\section{Conjugated Linoleic Acid}

- Only one study investigating the acute use of CLA on satiety found it suppressed hunger compared to a control oil, even in small amounts(Coleman, Quinn, and Clegg 2016).

- Satiety-independent effects on weight loss(Blankson et al. 2000; Belury, Mahon, and Banni 2003; Gaullier et al. 2007).
- Chronic studies indicate no effect on satiety(Blankson et al. 2000; Belury, Mahon, and Banni 2003; Gaullier et al. 2007).

- Lack of short-term data investigating effects regarding appetite, more studies needed to draw conclusions.

- Possible deleterious effects related to insulin resistance(Medina et al. 2000; Ulf Risérus et al. 2002; Smedman and Vessby 2001).

\section{Short Chain Fatty Acids}


- Various mechanisms by which SCFA can regulate satiety, including stimulation of satiety hormones(Psichas et al. 2014; Tolhurst et al. 2012; Samuel et al. 2008), intestinal gluconeogenesis(Bienenstock, Kunze, and Forsythe 2015b; De Vadder et al. 2014) and gastric emptying. Could possibly be additive with other functional lipids or foods with satiating properties(Liljeberg and Björck 1996; Darwiche et al. 2001). result in a strong satiety signal.

- Shown to be effective when replacing other fats in the diet in an ad libitum protocol. Beneficial as DAG does not require set doses to elicit its effects(Kawashima et al. 2008).
- Mode of delivery varies between studies, so the determination of the effects of each different mode is difficult.

- Many confounding factors, effects reported previously possibly not due to SCFA(J Darzi, Frost, and Robertson 2012; J Darzi et al. 2014).

- Low tolerability and palatability of acetate means effects are not necessarily related to satiety(J Darzi et al. 2014).

- No study to date has investigated the oral delivery of butyrate, no data on its effects.

\section{Diacylglycerol}

- DAG used in previous studies no longer in production, and to the knowledge of the author, there is currently no other available source. Until another DAG is produced, this, unfortunately, does not seem a feasible avenue of research.

- No chronic adaptation; must be used repeatedly for repeated acute effects(Yamamoto et al. 2001). 
- Possibly as good as a steroidal treatment in increasing cancer patients' energy intakes in an attempt to reverse cachexia(Bruera et al. 2003; M D Barber et al. 1999; Jatoi et al. 2004).

- Widely available.
- Possibly needs supplementation to induce effects, no acute effect.

- Various fish oil supplements commercially, with various concentrations and ratios of EPA:DHA, and some may be more beneficial than others.

\section{Small particle lipid emulsions}

- Possible decrease in hunger when supplementing with Fabuless $^{\mathrm{TM}}$ (Burns et al. 2001, 2000, 2002), but most studies do not corroborate this(H. J. Smit et al. 2012; Y.-K. Chan et al. 2012).

- Strong evidence that droplet size can be linked to the ileal brake(Knutson et al. 2010; Hussein et al. 2015; Seimon et al. 2009).
- The only commercially available SPL has little evidence of its efficaciousness(H. J. Smit et al. 2012; Y.-K. Chan et al. 2012), other SPL are manufactured specifically for studies.

- A suitable emulsion still needs developing.

- Evidence supporting droplet size and the ileal brake focuses mainly on the intragastric administration of the SPL which are not feasible methods of increasing satiety. 